\title{
DERECHO DE CONTRATOS Y EXCEPCIONALIDAD: REAPARICIÓN DE INSTITUCIONES Y RETORNO A LOS PRINCIPIOS EN CONTEXTO DE COVID-19
}

CONTRACT LAW AND EMERGENCY: INSTITUTION RECYCLE AND RETURN OF PRINCIPLES IN COVID-19 CONTEXT

\section{Edison Ramiro Calahorrano Latorre*}

Resumen: El presente trabajo analiza los efectos de la pandemia Covid-19 en el Derecho de Contratos, específicamente el incumplimiento objetivo y los remedios contractuales en contexto de excepcionalidad. Este estudio es de carácter dogmático y se utiliza el método analítico y comparado. Se parte por verificar si la pandemia Covid-19 constituye caso fortuito, para lo cual se analiza si dicho fenómeno y sus consecuencias reúnen los requisitos de externalidad, imprevisibilidad e irresistibilidad. A partir de esta respuesta se exploran remedios contractuales como la teoría de la imprevisión o la frustración del fin del contrato, su relación con el principio de pacta sunt servanda y la manera en que han sido evocados en la legislación emanada en emergencia, para lo cual se desarrolla un análisis comparado de la regulación del contrato de arrendamiento de inmuebles. Posteriormente se analiza la naturaleza de los principios como fuentes del Derecho y su aplicación en el derecho privado. Se concluye que el derecho por contratos en la excepcionalidad recurre a los principios, entendidos como racionalización de las reglas, lo que permite flexibilizarlas en búsqueda de soluciones a la complejidad.

Palabras clave: Covid-19, teoría de la imprevisión, frustración del fin del contrato, derecho de contratos, caso fortuito

\footnotetext{
* Doctor en Derecho (c) por la Universidad de Talca (Chile). Magíster en Políticas Públicas, Facultad Latinoamericana de Ciencias Sociales (Quito, Ecuador). Becario de Doctorado Nacional ANID-Chile. https://orcid.org/0000-0003-0408-5737. ecalahorrano@utalca.cl
} 
Abstract: This paper analyzes the effects of the Covid-19 pandemic on Contract Law, specifically objective non-compliance and contractual remedies in the context of exceptionality. This study is dogmatic using analytical and comparative methods. The starting point is to verify whether the Covid-19 pandemic constitutes an act of God, by analyzing whether this phenomenon and its consequences meet the requirements of externality, unpredictability and irresistibility. From this response, contractual remedies are explored, such as rebus sic stantibus or the frustration of purpose of contract, its relationship with the principle of Contract Law pacta sunt servanda, and how they have been evoked in the legislation issued in exceptionality, for which a comparative analysis of the regulation of the leasing contract is developed. The nature of the principles as sources of law and their application in private law is then analyzed. Finally, it is concluded that contract law in exceptionality resorts to principles, understood as the rationalization of the rules, which allows for flexibility in the search for solutions to complexity.

Keywords: Covid-19, Rebus Sic Stantibus, Frustration of Purpose of Contract, Contract Law, Act of God

Summary. I. Introducción. II. ¿El Covid-19 es un caso fortuito? Efectos en algunos contratos. III. Cuando las reglas no son suficientes. Algunos remedios que explorar. III.1. Teoría de la Imprevisión. III.2. Teoría de la frustración del fin del contrato. IV. Legislar desde la emergencia y retorno a los principios. V. Lecciones del Covid-19 ¿Un derecho de contratos por principios? VI. Conclusiones. Referencias.

\section{INTRODUCCIÓN}

El advenimiento de Covid-19 como pandemia a escala global se convirtió rápidamente en un desafío para la normalidad de las transacciones.

Nos encontramos en una etapa en que los efectos de la pandemia sobrepasaron el ámbito exclusivo de la salud trasladándose al plano jurídico y económico provocado por el cese de la actividad no esencial y el confinamiento domiciliario en el contexto de una cuarentena precedida por la declaratoria de estado de excepción.

La preocupación por la seguridad de las transacciones, generalmente respaldadas contractualmente sobrevino frente a la incerteza. 
Después de dieciocho días de haberse decretado en Chile el estado de excepción constitucional de catástrofe ${ }^{1}$ se escribía una reflexión que presagiaba el escenario inmediatamente posterior del derecho de contratos "muy probablemente debamos pensar que el derecho de los contratos está diseñado para situaciones de normalidad o, al menos, no de anormalidad estructural de carácter global y, si es así, la pregunta sería ¿cómo imaginar arreglos institucionales para períodos radicalmente anómalos a escala global?" (De la Maza, 2020).

Los últimos meses se ha intensificado el debate sobre la figura aplicable frente al incumplimiento de las obligaciones contractuales, especialmente las más cotidianas como el arrendamiento de inmuebles para vivienda o con fines comerciales. No nos referimos a la situación de los contratos de trabajo que requiere un análisis más profundo y ajeno a las pretensiones del presente estudio.

En este punto, ha surgido la interrogante respecto a si el Covid-19 o los efectos de las medidas asociadas a evitar su expansión encajan en los requisitos de la fuerza mayor como exoneración de la responsabilidad por incumplimiento de las obligaciones contractuales, a saber, que el hecho sea externo, imprevisible e irresistible ${ }^{2}$; llevándose una buena parte del debate el tercero.

Asumiendo que la pandemia o, con mayor precisión, un acto de autoridad dictado por motivo de esta tiene la entidad para exceptuar a una de las partes de cumplir con sus obligaciones, ¿podría existir una solución menos gravosa?

Este cuestionamiento ha concentrado la discusión respecto a la teoría de la imprevisión. Se suman a la búsqueda de racionalidad de los efectos de la pandemia otros criterios derivados del principio de buena fe contractual como la frustración del fin del contrato.

La ausencia de respuestas de aquellos códigos inspirados en el Code francés fundamentado en la intangibilidad del contrato se confronta con opciones como la renegociación o terminación ante el incumplimiento

\footnotetext{
${ }^{1}$ Presidencia de la República de Chile, Decreto 104/2020, 17-III-2020.

${ }^{2}$ En el caso chileno, el art. 45 del Código Civil define el caso fortuito o fuerza mayor como «se llama fuerza mayor o caso fortuito el imprevisto a que no es posible resistir, como un naufragio, un terremoto, el apresamiento de enemigos, los actos de autoridad ejercidos por un funcionario público, etc.», la misma redacción se repite en el art. 30 del Código Civil ecuatoriano, art. 64 del Código colombiano, todas normas adaptadas del Código de Andrés Bello con gran influencia del Code francés decimonónico. En todos los casos analizados nos encontramos frente a la definición de un hecho externo, imprevisible e irresistible con un efecto general de eximir de la responsabilidad a la parte que ha incurrido en incumplimiento de sus obligaciones contractuales por esta causa.
} 
objetivo emanadas de principios generales como la buena fe contractual, el equilibrio y justicia contractual; o, inclusive, la equidad natural.

Estas disquisiciones son el objeto del presente trabajo que busca responder el problema ¿cómo deben aplicarse los principios en el derecho de contratos, cuando el Derecho Común es insuficiente? ¿Se pueden aplicar figuras como la teoría de la imprevisión o la frustración del fin del contrato sin estar expresamente legisladas y bajo qué fundamento?

La hipótesis de la que se parte es que los principios constituyen fuentes del derecho de contratos, por lo que, de ellos pueden emanar reglas jurídicamente válidas para atender situaciones de hecho excepcionales provocadas por la pandemia o justificar la aplicación de figuras que no tienen expresa regulación legal como la teoría de la imprevisión o la frustración del fin del contrato.

Si lo manifestado es correcto, el objeto de estudio que permitirá comprobarlo es la normativa que se ha dictado en materia contractual durante la pandemia, en la que aparecen figuras anómalas aparentemente fundamentadas en principios, como suspensión temporal de obligaciones, prohibiciones de resolución, modificaciones en el modo de cumplimiento de las obligaciones, entre otros.

Metodológicamente este estudio es de carácter dogmático y confrontará doctrina autorizada y jurisprudencia respecto de la normativa dictada en emergencia en casos seleccionados. Por lo señalado se utilizarán el método analítico y comparado.

El primer apartado analizará los requisitos y condiciones que convierten, o no, al Covid-19 y sus efectos en un caso fortuito.

En segundo lugar, se analizarán la teoría de la imprevisión y la teoría de la frustración del fin del contrato, como los principales remedios propuestos por la doctrina en la excepcionalidad. Acto seguido, por el carácter limitado de este trabajo, se ilustrará con el ejemplo de los contratos de arrendamiento de vivienda y comercial, que han sido los que más debate ha traído en la literatura revisada, por lo que se deja el análisis de otros importantes como los de consumo o prestación de servicios para otras investigaciones. Finalmente, se configurará una propuesta de funcionamiento del derecho de contratos por principios que puede ser de utilidad para el juzgador. 


\section{II. ¿EL COVID-19 ES UN CASO FORTUITO? EFECTOS EN ALGUNOS CONTRATOS}

Los contratos son instrumentos indefectiblemente proyectados para el futuro, distribuyen riesgos entre las partes y establecen cómo éstas deberán soportar los efectos de su posible materialización; labor en la que se debe procurar el equilibrio en las obligaciones mutuamente pactadas y las respuestas que las partes ofrecerán ante los imprevistos. Las partes pueden decidir que una de ellas se haga cargo de estos efectos; o, por el contrario, pueden compartir esta carga.

La fuerza mayor o caso fortuito, que en Chile se entienden como sinónimos (Brantt, 2010), cobra importancia como causa que exime de la responsabilidad al deudor frente al incumplimiento de sus obligaciones contractuales $^{3}$. El caso fortuito es eximente de responsabilidad también frente a casos de responsabilidad objetiva (Pizarro, 2010), en los que ni siquiera el actuar diligente del deudor le sirve como justificación; por lo que se constituye como límite frente a la responsabilidad por el incumplimiento. Lo señalado provoca que la posibilidad del deudor de acogerse a esta causal sea limitada y cumpla con requisitos estrictos; caso contrario, estaríamos afectando al núcleo mismo de la noción de pacta sunt servanda, y la buena fe contractual ${ }^{4}$.

El Código Civil chileno en el art. 1547 inciso cuarto otorga a las partes la facultad de establecer cláusulas específicas que regulen el caso fortuito o fuerza mayor en el contrato, los requisitos para su consideración y los efectos, como parte de la distribución de riesgos que éste regula. Según palabras de Tapia (2020) el alcance de esta distribución requiere aplicar las reglas de interpretación contractual contenidas en el art. 1560 del Código; y,

${ }^{3}$ El art. 1547§2 del Código Civil chileno señala:

«El deudor no es responsable del caso fortuito, a menos que se haya constituido en mora (siendo el caso fortuito de aquellos que no hubieran dañado a la cosa debida, si hubiese sido entregada al acreedor), o que el caso fortuito haya sobrevenido por su culpa».

${ }^{4}$ En el caso chileno la buena fe contractual está señalada en el art. 1546 del Código Civil, norma que expresamente alude a la facultad integradora de este principio, por cuanto señala que los contratos obligan no sólo a lo escrito en ellos «sino a todas las cosas que emanan precisamente de la naturaleza de la obligación, o que por la ley o la costumbre pertenecen a ella». Precisamente de la amplitud de este principio surgen figuras como la cláusula rebus sic stantibus. Sobre la buena fe objetiva y su función integradora en la jurisprudencia chilena (Corral, 2007) 
una vez desentrañado dicho alcance, aplicar las normas supletorias del derecho común sobre la materia.

¿Hasta dónde puede llegar la autonomía de las partes en sede contractual, en lo que respecta a la regulación del caso fortuito?, se entiende que las facultades son amplias; por ejemplo, que las partes pacten que una de ellas asuma unilateralmente los efectos del imprevisto ${ }^{5}$, lo que se conoce comúnmente como cláusula de indemnidad o modificatoria de la responsabilidad (Cárdenas \& Reveco, 2018); que pueden ser agravatorias, como la antes mencionada o restrictivas si atenúan o eximen de la responsabilidad al deudor como parte del pacto previo ${ }^{6}$.

En el caso de que nada se haya pactado por las partes, opera el régimen general y subsidiario del Código Civil a su silencio. En este régimen general se pueden identificar dos funciones del caso fortuito en el ámbito contractual; en primer lugar, eximir del pago de indemnización de perjuicios por el incumplimiento al deudor, función que también es aplicable en el ámbito extracontractual y afecta a la responsabilidad; y, en segundo lugar, extinguir una obligación, si el caso fortuito o fuerza mayor es definitivo, o permitir al deudor la suspensión en el cumplimiento de la obligación, si el hecho que suscita el caso fortuito o fuerza mayor es temporal (Tapia, 2020).

El art. 1547 inciso segundo del Código señala dos excepciones al efecto eximente anteriormente mencionado que son, la constitución en mora del deudor o que el caso fortuito haya sobrevenido por su culpa.

Este segundo punto se enlaza con los requisitos para considerar un hecho como caso fortuito que están contenidos en el art. 45 del Código Civil, específicamente con el primero, la externalidad ${ }^{7}$, es decir, que no haya sido la conducta del deudor la que haya provocado el hecho que se pretende presentar como caso fortuito. El hecho debe ser externo al deudor (Pizarro,

\footnotetext{
${ }^{5}$ Un ejemplo de este razonamiento se encuentra en la sentencia Corte de Apelaciones de Santiago, Rol 4.996-13 de 4-VI-2014, en el que se señala que en el contrato de transporte en cuestión la parte deudora había asumido el hecho que se presentaba como caso fortuito o fuerza mayor, respecto a pérdida de mercadería.

${ }^{6}$ El Código Civil francés en su art. 1351 señala como efecto del incumplimiento del deudor, por concurrir un hecho de fuerza mayor o caso fortuito, la extinción de su obligación, a menos de que se haya acordado asumirla. Esta misma facultad de las partes para pactar la modificación de la responsabilidad ante un hecho de caso fortuito o fuerza mayor se encuentra contenida en el cuarto inciso del art. 1547 del Código Civil chileno.

${ }^{7}$ Algunos fallos en Chile que han abordado el requisito de externalidad del hecho que se configura como caso fortuito o fuerza mayor son: Corte Suprema, Rol 1913-2004 de 24VIII-2006; Corte de Apelaciones de Santiago, Rol 5410-08, 8-X-2009, Corte Suprema, Rol 2448-10, 12-VI-2013; Corte Suprema, Rol 40.703-2017 de 17-VII-2019.
} 
2010) y esa externalidad se puede medir a partir del alejamiento del mismo respecto del alcance de sus obligaciones ${ }^{8}$.

La externalidad como elemento del caso fortuito ha sido reconocida en la doctrina chilena (Brantt, 2010) desde su perspectiva subjetiva, por lo cual se considera que el hecho es externo al deudor si está fuera de su voluntad, es decir, de la culpa, según lo que sugiere el art. 1547 del Código Civil en su segundo inciso ${ }^{9}$. La culpa que corresponde en el caso de contratos que contienen obligaciones recíprocas, que son los que más, es la leve, atribuible al estándar de conducta de una persona razonable ${ }^{10}$ (Tapia, 2020). Esta valoración se la hace in abstracto, es decir, se confronta la conducta del deudor frente a la que hubiera adoptado una persona razonable en las mismas circunstancias. Se califica, por lo tanto, si el hecho que provoca el incumplimiento del deudor está, o no, producido por una conducta culpable del mismo, en el sentido de que dicho hecho pudo preverse al momento de la suscripción del contrato. Finalmente, la calificación in abstracto debe tomar en cuenta variables como las circunstancias externas y la calificación del deudor para elevar o reducir es estándar de la conducta con la que se compara.

Una segunda manera de abordar la externalidad se refiere a la perspectiva objetiva fundamentada en la causalidad. Esta segunda señala que un hecho es externo al deudor si no existe relación causal entre la conducta de éste y su producción. Según lo señalado, si el hecho que impide el cumplimiento de la obligación por parte del deudor no tiene ninguna contribución de éste y es producido por un acontecimiento fuera de su

\footnotetext{
${ }^{8}$ El Code francés de 1804 ya se refería en su art. 1147 a que el deudor solo podía eximirse de la responsabilidad debido a una causa extraña a su actuar. El art. 1218 del Codice Civile italiano de 1942 precisa esta noción al señalar que el hecho eximente de responsabilidad por caso fortuito o fuerza mayor no debe ser imputable al deudor. Finalmente, el Código Civil francés de 2016 se refiere a que el hecho no debe estar bajo control del deudor; mientras que el art. 1732 del Código Civil y Comercial de la Nación Argentina de se refiere al requisito de la externalidad como aquel no imputable al deudor, siguiendo la fórmula italiana.

${ }^{9} \mathrm{Al}$ respecto se pueden señalar las consideraciones de Abeliuk (2014). En el mismo sentido se adscribiría (Coustasse e Iturrá, 1958) al señalar:

«el caso fortuito descansa sobre la valuación de la conducta del agente frente al suceso dañoso, esto es, sobre la determinación de si el deudor empleó o no la debida diligencia y cuidado en el cumplimiento de su obligación, en la prevención y en la resistencia frente a dicho evento» (p. 13).
}

Más recientemente se adhiere a esta tesis (Tapia, 2020).

${ }^{10}$ Sobre la noción de razonabilidad en el Derecho chileno se recomienda referirse a (San Martín, 2018). 
control, cumpliría el primer requisito de la fuerza mayor; porque este hecho no es causado por el deudor (San Martín, 2019, p. 128).

El deudor, por lo tanto, no se exime de responsabilidad o cumplimiento de la obligación si el caso fortuito es producido por su culpa; o, cuando el mismo tiene un vínculo causal objetivo con la conducta de éste (Baraona, 1997). Las dos visiones se relacionan con la concepción subjetiva y objetiva de la externalidad del caso fortuito (Brantt, 2009, p. 56).

La consideración objetiva de la externalidad es común en los instrumentos de unificación del Derecho de Contratos; así, por ejemplo, el art. 79.1 de la Convención de Viena sobre los Contratos de Compraventa Internacional de Mercaderías se refieren a que el hecho pretendido como caso fortuito debe estar ajeno a la voluntad del deudor; sin embargo, en su versión en inglés se señala beyond his control, por lo tanto, la doctrina (Vidal, 2005) ha concluido que la norma busca que el hecho debe estar fuera de la esfera de los riesgos de su actividad ${ }^{11}$. En similares términos se puede encontrar este requisito en el art. 8:108 de los Principios de Derecho Europeo de los Contratos, art. 7.1.7 de los Principios Unidroit y art. 3:104 del Draft Common Frame of Reference of European Contract Law (DCFR) ${ }^{12}$. Finalmente, en el ámbito regional, los Principios Latinoamericanos de Derecho de los Contratos (PLDC) señalan en el art. 86 que el hecho debe ser ajeno al control del deudor. Por su parte, el Código Civil y Comercial de la Nación Argentina en su art. 1730 no menciona a la externalidad como requisito; y, finalmente, el Código Civil brasileño en su art. 393 señala que el caso fortuito es un acto "necesario" que se refiere a la relación de causalidad entre éste y el incumplimiento. En todo caso, a pesar de que la tendencia legislativa y unificadora más actualizada se decanta por la noción objetiva de definir la externalidad desde el riesgo, algo que no sucede de manera generalizada en Chile; sin embargo, parte de la doctrina ha identificado el problema de la externalidad del caso fortuito en la causalidad y no en la culpa (Pizarro, 2005, p. 118).

\footnotetext{
${ }^{11}$ Comisión de las Naciones Unidas para el Derecho Mercantil Internacional, Convención de las Naciones Unidas sobre los Contratos de Compraventa Internacional de Mercaderías, 11-IV-1980, ratificado por Chile el 3-X-1990.

${ }^{12}$ En este documento hay un amplio comentario sobre la noción de ajenidad del hecho que se constituye como caso fortuito para funcionar como eximente de responsabilidad o cumplimiento de la obligación. La noción objetiva de externalidad es muy rigurosa, por cuanto excluye los otros requisitos referentes a la imprevisibilidad e irresistibilidad; tras la verificación de que el hecho estuvo en la esfera del control del deudor, aunque imprevisible e irresistible, éste responderá de manera absoluta. El texto compromete de manera especial a los deudores que tienen un deber objetivo de cuidado (Grupo de Estudio para un Código Civil Europeo, 2008).
} 
El segundo requisito del caso fortuito es la imprevisibilidad, sobre la cual existen también una noción clásica y otra contemporánea. La primera se fundamenta en la comparación del actuar de la persona que comete el hecho frente a otra razonable en las mismas circunstancias; analiza además las medidas que ésta haya tomado para evitar el suceso; finalmente, éstas son evaluadas al momento de la ejecución del contrato (Tapia, 2020). Esta noción adolece de no tomar en cuenta el deber de diligencia debida que tienen determinados agentes en ciertas relaciones contractuales, pero además, confunde la imprevisibilidad con la irresistibilidad al evaluar las medidas de precaución.

La principal crítica a esta noción clásica es el entendimiento de la imprevisibilidad como algo absoluto, desde un prisma abstracto; por cuanto, en la realidad, las circunstancias en las que se produce el hecho son relevantes e influyen en la posibilidad de prever o no el hecho. Entender la imprevisibilidad en términos absolutos convertiría en previsibles ${ }^{13}$ hechos tan adversos como la pandemia, puesto que, en abstracto, un contratante extremadamente diligente hubiera podido dar seguimiento a las publicaciones científicas de expertos en virología durante los últimos quince años y saber que este fenómeno podía producirse en cualquier momento ${ }^{14}$. Por otro lado, la verificación de las medidas de precaución para la calificación de la imprevisibilidad no solo incurre en la confusión con la irresistibilidad sino que se concentra en la ejecución del contrato, cuando la verificación de la misma realmente obedece a lo que pudo preverse al momento de que éste se celebró. Solo así puede ser útil el criterio de previsibilidad frente a figuras como la teoría de la imprevisión.

La manera moderna de entender la previsibilidad se concentra en la definición del estándar de comportamiento exigible al deudor, según las circunstancias en las que se encontraban las partes al momento de celebrar el contrato. Bajo estos parámetros relativos se puede comprender si el hecho pudo o no preverse. Lo señalado explica por qué el Código Civil francés de 2016 introduce en su art. 1218 el término razonable, como adjetivo para

\footnotetext{
${ }^{13}$ La jurisprudencia chilena sobre el tema es relevante, a partir de desastres naturales ocurridos en el país. En estos fallos se llega a entender que la previsibilidad encuentra su función como requisito del caso fortuito y eximente de responsabilidad si se la entiende desde las circunstancias en que se produce; puede consultarse en: Corte Suprema de Chile, Rol 40166-2017, 21-I-2019; Rol 5094-2017, 17-I-2018; y Rol 2296-2013, 19-XI-2013.

14 Efectivamente, desde el 2003 se ha venido anunciando esta posibilidad desde los especialistas, inclusive hace un año hay una compilación detallada de la investigación científica sobre coronavirus en murciélago (Fang Lim, Chengfa, Pascoe, How \& Chan, 2019) que, a los más rigurosos, proporcionaría un argumento de que el hecho podía preverse y debía estar reflejado en el texto de los contratos, al menos, los más complejos.
} 
calificar la imprevisibilidad (Viney, 2016). La razonabilidad enmarcada en la noción relativa de imprevisibilidad del caso fortuito es definida en el art. 1:302 de los Principios de Derecho Europeo de los Contratos como

«En especial, para determinar aquello que sea razonable, habrá de tenerse en cuenta la naturaleza y objeto del contrato, las circunstancias del caso y los usos y prácticas del comercio o del ramo de actividad a que el mismo se refiera».

También aparece la evocación a lo razonable en el Draft Common Frame of Reference of European Contract Law 3:104 (1).

La apreciación de la previsibilidad debe hacerse in abstracto, es decir, comparando la actuación del sujeto con la de una persona razonable en sus mismas circunstancias ${ }^{15}$ y con una calificación o especialidad equivalente (Tapia, 2020) ${ }^{16}$.

La imprevisibilidad está ligada además con la probabilidad, lo cual reviste de realidad dicho término:

«en efecto, si la diligencia requerida es la máxima, habrá que considerar como previsibles para el deudor tanto aquellos hechos cuyo grado de probabilidad, debido a la frecuencia con que se presentan, sea sobre todo alto, como otros que pueden no ser tan frecuentes, pero que la diligencia superior impuesta al deudor obliga igualmente tomar en cuenta, de modo tal que el ámbito de lo imprevisible resulta reducido» (Brantt, 2011, p. 61).

La probabilidad resulta un criterio objetivo y cuantificable para verificar que un hecho ocurra, en este caso, se relacionan su frecuencia o excepcionalidad; igualmente, la jurisprudencia sobre desastres naturales en Chile permite aclarar los requisitos de un hecho en base a su probabilidad ${ }^{17}$. El fallo de la Corte de Suprema de Chile Rol 12.169-2017 de 9 de noviembre de 2017 señala que:

«la imprevisibilidad implica que en condiciones normales haya sido imposible para el agente precaverse contra él. En cada caso se requiere: a) el

\footnotetext{
${ }^{15}$ A pesar de que esta noción equivaldría a la culpa leve desarrollada en el art. 44 del Código Civil chileno, o el cuidado de un buen padre de familia, los documentos más actualizados como los referentes a la unificación de los contratos asumen el término anglosajón reasonableness, que aparece, por ejemplo, en la sección 6-107 del Uniform Commercial Code de los Estados Unidos respecto a los esfuerzos del deudor por cumplir.

${ }^{16}$ Esta noción de la previsibilidad es acogida en algunos fallos como Corte Suprema de Chile, Rol 6739-07, 29-I-2009; Corte de Apelaciones de Concepción, Rol 74-11, 21-IV2011; Corte de Apelaciones de Valparaíso, Rol 593-16, 15-VI-2016.

17 Corte Suprema, Rol 40166-2017, 21-I-2019; Rol 5094-2017, 17-I-2018; Rol 121692017, 9-XI-2017; y Rol 2296-2013, 19-XI-2013.
} 
referente a su normalidad y frecuencia; b) el atinente a la probabilidad de su realización; c) el concerniente a su carácter excepcional y sorpresivo».

En el caso mencionado, un hecho que, aparentemente, cumpliría el requisito de imprevisibilidad como un tsunami, no lo haga, bajo las características geológicas de Chile y el tiempo de realización desde ocurrido el terremoto; lo que lo convierten en un hecho previsible, aunque no determinable. El fallo de la Corte Suprema de Chile Rol 76.472-2016 de 21 de noviembre de 2017 llega similares conclusiones analizando un hecho aún más improbable como es el terremoto. Otro criterio utilizado para determinar la imprevisibilidad es verificar la frecuencia de un hecho, por cuanto es más difícil para el deudor prever algo que no es esperable estadística o cuantitativamente (Brantt, 2010). Los eventos de extrema intensidad, por lo general, pueden enmarcarse como imprevisibles al ser cuantitativamente improbables; así un terremoto puede ser previsible, de hecho, así se ha institucionalizado para los contratos de construcción en Chile (Pizarro, 2010); pero un movimiento anómalamente violento es más difícil de esperar $^{18}$.

Mauricio Tapia (2020), después de hacer un minucioso recuento de los fenómenos pandémicos en la Historia concluye que el periodo de retorno entre los mismos es corto, lo que arrojaría una aparente previsibilidad:

«En términos aproximados, es posible constatar que, en promedio, cada $4 \mathrm{o}$ 5 años el mundo se enfrenta a sucesos similares. La misma circunstancia de que la OMS disponga incluso de una nomenclatura y gradación para ellos (emergencia sanitaria con alcance internacional, pandemia global, etcétera), da buena cuenta de su reiteración en el tiempo. Desde esta perspectiva, entonces, al menos en términos estadísticos, es previsible que fenómenos de una naturaleza similar al Covid-19 se repitan con esa frecuencia e impacten a más de un país».

Existen registros de pandemias con influencia global cada cierto tiempo como el SARS en 2003, MERS en 2014, ambas con expansión global

\footnotetext{
${ }^{18}$ Como conclusión de la abundante jurisprudencia chilena emanada desde el año 2010 con el terremoto de 27 de febrero (Tapia, 2020) señala:
}

«En cuanto a la jurisprudencia post terremoto de 2010, si nos remitimos a lo resuelto por la Corte Suprema, pueden extraerse, hasta la fecha (hay varias instancias en curso), dos conclusiones generales: por una parte, hay grupo importante de fallos ejecutoriados que consideran que es imprevisible el terremoto, pero que no lo sería el posterior tsunami y sus consecuencias; y, por otra parte, existe un conjunto de decisiones que declara incluso previsible el terremoto, por la naturaleza sísmica del país (que se demuestra, entre otras, por las normas de construcción antisísmicas aludidas), y por la creación de órganos públicos especializados para actuar frente a estas contingencias, incluso aquellas de la magnitud del terremoto de 2010» (p.79). 
y características nocivas; sin embargo, un fenómeno como el actual que obligue a aislamiento domiciliario a grandes grupos humanos y paralice la vida económica de ciudades enteras, probablemente solo se asemeje a otros ocurridos hace más de cincuenta o cien años como la gripe española o la gripe de Hong Kong (Tapia, 2020); por otro lado, contribuye también a su encasillamiento como caso fortuito el desconocimiento generalizado sobre sus características, por cuanto apenas se tiene una aproximación general respecto de sus síntomas y secuelas. Por lo señalado se puede sostener la calificación de Covid-19 y sus efectos como imprevisibles, por lo menos para los contratos vigentes antes que la emisión de los actos de autoridad o previos al momento en que se podía determinar la inminente llegada del virus al país, aunque, probablemente, la imprevisibilidad ya no sea un elemento fácilmente apreciable ahora que han transcurrido algunos meses.

Esto último nos lleva a determinar el momento del iter contractual en que debe verificarse la imprevisibilidad, siendo unánime la respuesta de que es a la celebración del contrato, tanto porque es allí donde se plasma la negociación fijándose derechos y obligaciones para las partes y se produce la asunción de riesgo.

Un caso menos evidente sería el del contrato de adhesión, parte de la doctrina señala que en este caso no se podría hablar de imprevisibilidad ante el incumplimiento sino de causalidad (Contardo \& Cortez, 2019).

Finalmente corresponde analizar el requisito de irresistibilidad, respecto del cual también se puede verificar una acepción clásica que se identifica con la absoluta imposibilidad del deudor de cumplir; por lo que se excluye la posibilidad de su aplicación a mayor dificultad u onerosidad como caso fortuito; obligándose en este segundo caso el deudor a cumplir mediante la implementación de mayores esfuerzos (Abeliuk, 2010, t. II).

Una revisión más reciente de este requisito asume una posición relativa que se contrasta con la conducta exigible del deudor. Este postulado señala que la irresistibilidad no se refiere a un concepto absoluto, sino medido a través del prisma de la diligencia del deudor que obliga a resistir cualquier evento que pueda generar un incumplimiento, incluso los más imprevistos, como señala Brantt (2011). Por otro lado, esta discusión lleva a desentrañar cuál es la verdadera conducta exigible al deudor frente a un hecho que puede llevar al incumplimiento, ¿evitar que este suceda o resistir sus efectos una vez que se produce?, parece más adecuado inclinarse por la segunda opción al ser la que evoca el art. 45 del Código Civil chileno y complementar la imprevisibilidad; puesto que, éste último se concentra en el momento de celebración del contrato y se refiere a la capacidad de las partes para adelantarse al futuro y programar las respuestas a eventos que tienen una importante probabilidad de producirse y afectar el cumplimiento 
de las obligaciones contractuales. En contraste a los señalado, la irresistibilidad se refiere a la capacidad para aplicar remedios a hechos que no pudieron preverse al momento de contratar y se produjeron, pero que las partes, con un esfuerzo razonable que no implique un desequilibrio contractual importante, pueden atender para procurar el cumplimiento ${ }^{19}$.

En todo caso, en palabras de Brantt (2011) la irresistibilidad supone hacer lo necesario para que el hecho no afecte el cumplimiento; y de hacerlo, verificar si el deudor no tenía manera de resistirse al incumplimiento, sea postergándolo u ofreciendo un sustituto de igual calidad ${ }^{20}$.

Sobre la irresistibilidad se aplica el mismo modelo de apreciación que con la imprevisibilidad, es decir, se debe contrastar la diligencia del deudor, en abstracto, con la conducta de una persona razonable en sus circunstancias externas, incluyendo su calificación, grado de profesionalización y las posibilidades de resistir que tenía a su alcance. Por lo tanto, un evento puede constituir fuerza mayor en materia contractual si, siendo imprevisible y ajeno, un deudor diligente, en sus circunstancias externas, no pudo evitarlo o resistir ${ }^{21}$ su producción (Tapia, 2020).

En el ámbito contractual la jurisprudencia chilena reciente toma, además de la inevitabilidad, la necesidad de evaluar las medidas que se tomaron para resistir el incumplimiento ${ }^{22}$. La adopción de medidas para resistir el incumplimiento demuestra la diligencia debida y se convierte en

${ }^{19}$ Un ejemplo de lo mencionado podría aplicarse al contrato de prestación de servicios educacionales ante el fenómeno de Covid-19; los centros educativos se han valido de herramientas tecnológicas para procurar la enseñanza a distancia, cubriendo los elementos esenciales de ésta. Las medidas implementadas pueden representar un costo adicional en adquisición de licencias de software, capacitación a docentes, en herramientas virtuales; sin embargo han podido resistir el incumplimiento con ellas; otra discusión será si las mismas aseguran una similar calidad del servicio contratado, para lo que, de haber diferencias podrían aplicarse remedios como la reducción de precio o la resolución anticipada.

${ }^{20}$ El Uniform Commercial Code regula en su sección 2-614 una figura llamada Substituted Performance que señala que, ante el incumplimiento sin falta de una de las partes o la imposibilidad de cumplimiento en la manera pactada, pero que existe un commercially reasonable substitute este sustituto no solo podrá ser aplicado, sino que deberá ser aceptado por la contraparte. Un remedio parecido se observa en la Convención de Viena en su art. 37, en los arts. 9:101 2 (a) y 9:101 2 (b) de los Principios Europeos del Derecho de Contratos y el art. 3:706 del Draft Common Frame of Reference of European Contract Law, que regula la figura de substitute transaction.

21 El Código Civil francés en su art. 1218 opta por una redacción que fusiona las características de inevitabilidad e irresistibilidad del hecho al señalar que el mismo cumple el requisito si sus efectos no se pudieron evitar por medidas apropiadas del deudor. Por su parte, el Código Civil y Comercial de la Nación Argentina en su art. 1730 se refiere a que el hecho no puede ser evitado.

${ }^{22}$ Corte Suprema, Rol 76.461-2016, 5-IX-2017. 
un justificativo más claro para eximir al deudor de la responsabilidad, en el caso que el incumplimiento llegue a producirse de todas maneras; «en otros términos, de nada le servirá la alegación de que el hecho era inevitable, si la diligencia impuesta por el contrato exigía tomar medidas adicionales para de todas formas cumplir el contrato» (Tapia, 2020).

La irresistibilidad, a diferencia de la imprevisibilidad, tiene dos momentos de verificación; el primero se refiere a si el hecho pudo evitarse, para lo cual es clave indagar respecto de la celebración del contrato y la adopción de medidas destinadas a evitar el incumplimiento; como por ejemplo una cláusula hardship ${ }^{23}$, muy común en contratos complejos de larga duración que requieren flexibilidad en cuanto a su revisión. El segundo momento se refiere a la verificación de las medidas adoptadas para resistir el hecho, una vez producido, lo cual se produce en la ejecución del contrato.

En base a lo mencionado, se pueden ensayar algunas hipótesis respecto a la pandemia Covid-19.

Se parte primero de la premisa de que la pandemia no es en sí el hecho que puede configurarse en caso fortuito, sino los actos de autoridad como consecuencia de ella; sin embargo, como se anticipó, la generación de un fenómeno de esta magnitud y con alcance global es externo a cualquier comportamiento de hipotéticos deudores incumplidos; también sería inevitable, puesto que, si bien podía preverse un evento de similares características por personas altamente calificadas, es irreal afirmar que alguna persona pudiera señalar con seguridad un evento de dimensiones globales sin precedentes, al menos en los últimos sesenta años.

Por lo señalado, la doctrina que se ha manifestado hasta el momento ha volcado su atención hacia el requisito de hecho irresistible; lo que, de verificarse, permitiría calificar incumplimientos contractuales objetivos por caso fortuito o fuerza mayor (De la Maza \& Vidal, 2020, p. 145).

En España opera para el caso fortuito el art. 1105 que exime de responsabilidad al deudor por aquellos sucesos que no hubieran podido preverse o que previstos fueran inevitables, ante lo cual se ha señalado que

«es claro que la crisis del Covid-19 es un caso de fuerza mayor y que el factum principis de la declaración del Estado de alarma, impide que los daños y perjuicios

\footnotetext{
${ }^{23}$ Se entiende por tal aquella que prevé la capacidad de los contratantes para renegociar el contenido contractual ante circunstancias imprevisibles sobrevinientes. Sobre este tema se puede consultar (Elorriaga \& Santa María, 2017; Brunner, 2008; Momberg, 2010). La finalidad es restaurar el equilibrio contractual. Es común en los contratos de compraventa internacional y está regulada en los arts. 6.2.1 y siguientes de los Principios Unidroit, 1:110 del DCFR.
} 
provocados a una parte por la imposibilidad de cumplir el contrato por la otra deben ser indemnizados» (Ortí, 2020, p. 2).

En conclusión, nos encontramos frente a un caso fortuito en la concurrencia de los tres requisitos, lo cual no afecta a todos los casos contractuales, por lo que las generalizaciones pueden ser inexactas.

La dificultad que se suscita respecto al Covid-19 es que en muchos casos la irresistibilidad para cumplir no es definitiva sino temporal, mientras se mantenga una medida restrictiva de la movilidad como la cuarentena. Vale tomar como ejemplo el caso del contrato de arrendamiento de local comercial en el que, por un lado, se podría hablar del incumplimiento del arrendador respecto del art. 1924 numeral segundo del Código Civil chileno $^{24}$ que obliga al arrendador a mantener la cosa en el estado de servir para el fin a que ha sido arrendada. El problema radicaría en que el incumplimiento no se debe a hecho o culpa del arrendador o sus agentes, sino a un caso fortuito que es el acto de autoridad que prohíbe la actividad comercial o impide la misma por la medida sanitaria de cuarentena, es decir, al incumplimiento objetivo que no está previsto en el art. 1925, pero que eximiría al arrendador de pagar indemnización.

Por otro lado, el incumplimiento será temporal, mientras dure la medida, por lo que lo, en la finalidad de mantener la relación contractual, lo más requerido por la partes podría ser la suspensión temporal o la resolución anticipada, medidas que aparecen en la normativa ad-hoc que se analizará más adelante.

Otros contratos tendrán un panorama gris, por cuanto la irresistibilidad no aparece tan clara, pero a una de las partes se le convierte el cumplimiento de sus obligaciones en excesivamente oneroso, ante lo cual es necesario aproximarse al análisis de la teoría de la imprevisión. En algunos casos, lo que sucedería es la frustración del fin del contrato, afectando a dos requisitos primordiales como son el objeto y la causa. En los dos capítulos posteriores trataremos de hacernos cargo de ello con la base de la discusión que se ha producido hasta esta fecha, siempre presente que el tema está en pleno desarrollo.

\footnotetext{
${ }^{24}$ El análisis opera de manera similar para los arts. 1982, num. 2, y 1983 del Código Civil colombiano y la regulación contenida en los arts. 1865, num. 2, y 1866 del Código Civil ecuatoriano.
} 


\section{CUANDO LAS REglaS NO SON SUFICIENTES. AlgunOS REMEDIOS QUE EXPLORAR}

En el apartado anterior concluimos que nos encontramos ante un hecho de caso fortuito cuando los actos de autoridad emitidos en razón de la enfermedad Covid-19 añaden la irresistibilidad a la imprevisibilidad y externalidad que caracteriza este fenómeno, aunque habrá contratos que se sigan cumpliendo, bien porque se ofrecen sustitutos comercialmente razonables, como en el caso de los contratos de servicios educativos; o porque la prestación no se ve afectada como en los servicios esenciales que, si bien han modificado la forma en que se cumple, no han afectado el cumplimiento de obligaciones. A continuación se analizarán dos instituciones que han sido invocadas por motivo de Covid-19 como soluciones, la teoría de la imprevisión y la teoría de la frustración del fin del contrato. Se han seleccionado para análisis específico, por cuanto ninguna se encuentra regulada en el Código Civil chileno.

\section{III.1. Teoría de la imprevisión}

Como señalamos anteriormente, que el hecho no sea irresistible no significa que no haya vuelto más costoso el cumplimiento, lo cual puede afectar el equilibrio contractual (López, 2015).

La intangibilidad de los contratos y el respecto al principio de pacta sunt servanda es la regla en Chile ${ }^{25}$, como señalan Elorriaga y López, (2017):

«Hasta hace poco ni un solo fallo de los tribunales ordinarios había admitido en nuestro país la revisión de un contrato en virtud del advenimiento de nuevas circunstancias. Incluso en el plano del Derecho Internacional Público, Chile se ha manifestado contrario a que se pueda horadar la fuerza obligatoria de lo pactado, invocándose por la parte afectada el cambio fundamental de las circunstancias».

La intangibilidad del contrato está establecida en el art. 1545 del Código Civil y la jurisprudencia de la Corte Suprema pocas veces se ha alejado de esta referencia ${ }^{26}$; a pesar de que existe cierta normativa que la

\footnotetext{
25 Este análisis es aplicable también al caso colombiano y ecuatoriano que manejan legislación similar en la materia.

${ }^{26}$ Corte Suprema, 10 de enero de 1925, Revista de Derecho y Jurisprudencia, t. 23, sec. 1, pág. 423. En este fallo la Corte Suprema señala: «(...) los tribunales carecen de facultades para derogar o dejar sin cumplimiento la ley del contrato, ya sea por razón de equidad o bien de costumbres o reglamentos administrativo (...)».
} 
evoca $^{27}$ La jurisprudencia chilena no se había referido a este tema hasta el año 2006 con la sentencia de la Corte de Apelaciones de Santiago en el caso Guillermo Larraín Vial con Servicio de Urbanización de la Región Metropolitana de 14 de noviembre ${ }^{28}$, efectivamente, previo a este fallo no se había receptado esta figura más que en sede arbitral. Según Alcalde (2007), a pesar de que la teoría de la imprevisión no se encuentra en la legislación puede haber una aproximación a la misma «a la luz de los principios generales del derecho y la exégesis contractual» (p. 362).

En la jurisprudencia chilena se puede citar también el fallo Rosas con Gutiérrez, Rol 941/2010 de 17 de enero de 2011 enmarcado en la construcción en el que las modificaciones se configuran, más bien, a través de pactos de las partes.

En un fallo reciente de la Corte Suprema de 20 de marzo de 2020 se discutió nuevamente respecto de la teoría de la imprevisión en el caso de un mal resultado por la inversión de dinero en una plataforma electrónica dentro del mercado extrabursátil que obligaba a contar con fondos por parte del inversionista para responder cualquier transacción negativa. En el caso, los fondos depositados no fueron suficientes para una pérdida cuantiosa que obligó a la intermediaria y demandante a pagar. Sobe la teoría de la imprevisión se señala:

«Esa situación, se podría enmarcar en lo que la doctrina denomina teoría de la imprevisión, doctrina de la imprevisión o excesiva onerosidad sobreviviente (...) En efecto, el profesor René Abeliuk (...) (1993, p. 699) define la imprevisión como la facultad del deudor de solicitar la resolución o revisión del contrato de ejecución postergada cuando un imprevisto ajeno a la voluntad de las partes ha transformado su obligación excesivamente onerosa».

A pesar de que se descarta para el caso concreto, la Corte no parece pronunciarse como contraria a la misma.

Un razonamiento favorable hacia la teoría se presenta también en la doctrina por Elorriaga y López (2017) que señala:

\footnotetext{
${ }^{27}$ Como sucede con el art. 2003 num. 2 del Código Civil que permite al empresario recurrir al juez para la revisión del contrato y determinación de un recargo por el advenimiento de mayor onerosidad por circunstancias desconocidas. Algo similar puede encontrarse en el art. 2180 que permite la restitución anticipada del comodato ante necesidad imprevista y urgente; o, en el art. 2227 num. 2 que faculta al depositante exigir la devolución anticipada de la cosa cuando corra peligro con éste.

${ }^{28}$ En este caso referente a un desequilibrio contractual en materia de construcción se reconoce que no existe un precepto que desarrolle la teoría de la imprevisión de manera expresa en el Código Civil; sin embargo, se recurre a principios de interpretación como la equidad natural contenida en el art. 24 y la prohibición del enriquecimiento injusto.
} 
«La aplicación inflexible del axioma pacta sunt servanda puede, sin embargo, conducir a resultados funestos e injustos para una de las partes contratantes. Por ello, no pocas legislaciones y tribunales extranjeros, al igual que la doctrina de los autores, incluidos civilistas chilenos, han buscado evitar o remediar las consecuencias intolerables del cambio de las circunstancias. Se conoce como teoría o doctrina de la imprevisión el estudio de los supuestos bajo los cuales los jueces estarían autorizados para prescindir de la aplicación del contrato al pie de la letra, y el estudio de las soluciones posibles al desajuste producido. Estas soluciones son fundamentalmente dos: la revisión judicial de los contratos y la resolución por excesiva onerosidad sobrevenida».

Los requisitos para la aplicación de la teoría de imprevisión radican, en primer lugar, en la existencia de un hecho imprevisible, para lo que aplican los argumentos anteriormente señalados para el caso fortuito; es decir, que se valore en abstracto en base a la diligencia debida que emana de las obligaciones del contrato y que no haya podido ser previsto al momento de celebrar el contrato. En segundo lugar, el cumplimiento de la obligación para una de las partes debe volverse excesivamente oneroso y romper el equilibrio del sinalagmático contractual; en este punto, se entiende que la mera dificultad para el cumplimiento no habilita a la aplicación de la teoría. Finalmente, el hecho imprevisible y que provoca la excesiva onerosidad no debe ser provocado por el deudor ${ }^{29}$.

La teoría de la imprevisión, por lo tanto, es una institución que puede convivir con el pacta sunt servanda, pero se configura como límite del

${ }^{29}$ El Código Civil francés, en su art. 1103 acoge el principio de pacta sunt servanda elevando la naturaleza del contrato a ley para las partes, lo que no obsta para que en el art. 1195 se acoja la teoría de la imprevisión y se faculte a la parte afectada a solicitar a la otra una renegociación del contrato; si esa afectación consiste en que su obligación se tornó excesivamente onerosa por un cambio imprevisible de las circunstancias al momento de contratar. Si la renegociación falla o se rechaza por la contraparte, las partes pueden acordar la terminación anticipada bajo las condiciones que determinen o pueden recurrir al juez, para que adapte el contrato. A falta de este acuerdo, una de las partes puede hacer la solicitud al juez, el cual podrá revisar o rescindir el contrato bajo las condiciones fijadas por éste. Según (Cabrillac, 2018) esta legislación acerca al modelo francés al moderno derecho de contratos especialmente influido por los proyectos europeos de unificación.

Este art. es muy amplio y otorga las facultades más amplias al juez, a diferencia de la interpretación jurisprudencial que se ha hecho en España de la cláusula rebus sic stantibus (como es más conocida en España la teoría de la imprevisión), que, en su primera fase desarrollada en fallos posteriores a la Guerra Civil, específicamente el STS, 1. a , de 17-V1957 (RJ 1957/2164) establece requisitos muy rigurosos

La jurisprudencia española más reciente aplicada, principalmente, a casos relacionados con la crisis económica de finales de la década pasada, la cual llegó a ser considerada como una causa imprevista que provoca excesiva onerosidad de una de las partes, a partir de la sentencia STS 644/2012 de 8-XI-2012 relativa a compraventa de viviendas y que se consolidaría en el fallo del Tribunal Supremo STS 1013/2013 de 17-I-2013. 
mismo, permitiendo a las partes renegociar por sí mismas el contenido del pacto y restablecer el equilibrio contractual, o en su versión más amplia, solicitar la revisión judicial del contrato, situación que podía haber sido escandalosa desde los principios del derecho de contratos del siglo XIX pero que se vuelve no solo recomendable sino necesaria en tiempos globalizados (Fernández, 2016).

Como se puede apreciar, una buena parte de los Códigos Civiles de Europa occidental han optado por legislar la excesiva onerosidad sobreviniente en el ámbito contractual, de igual manera ha sucedido en la región, como se constata en el art. 1091 del Código Civil y Comercial de la Nación Argentina ${ }^{30}$, el art. 1440 y siguiente del Código Civil peruano que además ofrece una amplia regulación de la figura no solo a contratos conmutativos de tracto sucesivo, sino además a los de ejecución inmediata con cumplimiento diferido y a los aleatorios en que la excesiva onerosidad no se haya producido por la conducta de una de las partes (Varsi, Rosenvald \& Torres, 2020, p. 34). Además, está presente en el Código Civil brasileño en los arts. 478 y ss.

El problema se suscita cuando no existe norma aplicable, como en Chile, Ecuador y Colombia ${ }^{31}$; en cuyo caso se ha recurrido a la aplicación de principios del derecho de contratos.

Sobre los fundamentos que se han esgrimido para explicar la pertinencia de la teoría de la imprevisión, Elorriaga y López (2017) rechazan como argumentos apropiados la cláusula rebus sic stantibus ${ }^{32}$, ya que a consideración del autor resulta artificial considerar que las partes pactaron inicialmente que pueda modificarse el contrato por no permanecer las mismas condiciones en que fue celebrado; el enriquecimiento sin causa al estar la causa justamente en el contenido contractual; y, el abuso de derecho,

\footnotetext{
${ }^{30}$ Sobre la eliminación del requisito de imprevisibilidad para la aplicación de la teoría de la imprevisión (Grasso, 2018) señala que permitiría una mayor aplicación práctica, frente a una jurisprudencia muy reacia a la aplicación de la misma, por ejemplo, en tiempos de crisis económica que ha sido una situación reiterada en el país.

${ }^{31}$ Colombia ha introducido la teoría de la imprevisión en el art. 868 del Código de Comercio que señala la institución aplicable frente a circunstancias extraordinarias, imprevistas e imprevisibles que alteren o agraven la obligación de una parte haciéndola excesivamente onerosa. Se aplica para contratos de ejecución sucesiva, periódica y diferida. Se regula únicamente la revisión judicial del contrato.

${ }^{32}$ La doctrina y jurisprudencia española suelen inclinarse por denominar así a la teoría de la imprevisión, denominación ésta, más bien, de origen francés. La cláusula rebus sic stantibus se traduce como "los contratos de tracto sucesivo se entienden permaneciendo las cosas en el mismo estado". A pesar de existir antecedentes romanos que se refieren a la facultad de renegociación ante hechos imprevisibles, la cláusula, como tal, se remonta a Bártolo y la escuela de los glosadores y postglosadores (Dörr, 1985; Rivera \& Barcia, 2016).
} 
tampoco presente en la figura analizada. Por otro lado, estos autores identifican mejores argumentos para explicar la teoría de la imprevisión en la buena fe contractual, la responsabilidad contractual y la libre investigación científica relacionada con el análisis respecto de la justicia contractual y los efectos económicos del contrato.

Por su parte, Momberg (2010) coincide también en la buena fe y la naturaleza del contrato como fundamentos de la facultad de revisión contractual; Alcalde (2007) considera que en la figura hay la presencia de los principios de intangibilidad del contrato, interdicción del enriquecimiento e interdicción de abuso del interés jurídicamente protegido.

La prevalencia del principio de intangibilidad de los contratos propio del Code francés de 1804 y el racionalismo positivista de finales del siglo XVIII y el siglo XIX desterró temporalmente esta figura de la legislación; no fue sino hasta entrado el siglo XX con los esfuerzos de Karl Larenz y la teoría de la base del negocio jurídico, que se retomó su importancia, bajo la constatación práctica de que el ideal del positivismo no pudo cumplirse, por cuanto la Ley y el contrato erigido como ley para las partes no podían prever la variedad de situaciones que pueden presentarse (Dörr, 1985). Este mismo principio consagrado en el art. 1545 del Código Civil habría sido la razón de mayor peso para su nula adhesión por parte de los tribunales en Chile hasta llegado el siglo XXI.

Como se puede observar, existe una confrontación de principios del derecho de contratos como trasfondo de los argumentos a favor y en contra de la teoría de la imprevisión, por cuanto desafía el pilar de la fuerza obligatoria de los contratos

\section{III.2. Teoría de la frustración del fin del contrato}

Dentro de los supuestos de eficacia sobrevenida del contrato, la teoría de la frustración del fin del contrato comparte con la teoría de la imprevisión la existencia de un hecho externo, imprevisible e irresistible que sucede de manera posterior a la celebración de éste y que no fue asumido como riesgo por ninguna de las partes en el pacto. A diferencia de la teoría de la imprevisión, en la que el hecho que constituye caso fortuito convierte a la obligación de una de las partes en excesivamente onerosa y obliga a la revisión del contrato; en el caso que nos convoca en este apartado, la causa del contrato se afecta, provocando que el cumplimiento del mismo devenga en ilegal, imposible o estéril económicamente.

Se puede ilustrar lo señalado con la revisión de los casos de dieron origen a la figura (frustration of purpose of contract) en el common law, para luego verificar cómo se ha expandido su regulación. 
El primer caso en el que se acuñó el término frustración fue Taylor $v$. Caldwell en 1863 (All Answers Ltd., 2018), en el que el primero demandó al segundo el pago de indemnización por incumplir el contrato de arrendamiento de una sala de conciertos que fue destruida por un incendio una noche antes de que empiece a usarse para distintas actividades programadas por el arrendatario. El juez moduló la regla de cumplimiento absoluto aplicada a los contratos que venían rigiendo en el derecho inglés desde, al menos, dos siglos atrás ${ }^{33}$ y señala que en el caso de los contratos que dependen de la existencia del objeto, no existe responsabilidad del locador si éste perece sin culpa, ya que constituía una obligación conocida desde la génesis misma del contrato (Beatson, Burrows \& Cartwright, 2016).

Se aplicó un similar razonamiento en el caso de los contratos intuite personae, considerándose que si éste depende de la prestación de servicios personales de una de las partes y ella no podía cumplirlos por muerte o enfermedad, existe caso fortuito ${ }^{34}$.

Los ejemplos señalados verifican ineficacia sobreviniente del contrato por destrucción de la cosa objeto del mismo o especificidad en los servicios de la contraparte; otros supuestos que pueden encajarse son la inaptitud sobrevenida del contrato para cumplir su misión económica, la destrucción del riesgo mercantil natural ${ }^{35}$, la ilicitud sobreviniente del objeto del contrato y la frustración de una condición implícita no expresada (Beatson, Burrows \& Cartwright, 2016).

A este último se refiere el leading case correspondiente a la figura de la frustración del fin del contrato, Krell v. Henry en 1903 (All Answers Ltd. 2018). Este responde a un conjunto de fallos denominados casos de la coronación, producidos a partir de la suspensión de la coronación del Rey Enrique VII, que iba a generar una serie de eventos, mismos que fueron pospuestos por enfermedad de éste. Henry solicitó en arrendamiento un piso en Pall Mall a Krell para observar el evento que posteriormente sería suspendido. En el contrato no se menciona que la finalidad del mismo es obtener una posición favorable para contemplar los actos previstos para la coronación; sin embargo, al posponerse los mismos, Krell demanda el cumplimiento y Henry reconviene por la devolución del anticipo cancelado.

\footnotetext{
${ }^{33}$ Desde el caso Paradine v. Jane en 1647 se estableció la regla de los contratos absolutos, por la cual, las obligaciones derivadas de un acuerdo no admitían excepciones respecto de su cumplimiento, ni siquiera por concepto de caso fortuito o fuerza mayor. Esta regla se establecía como garantía de todo pacto y se asentaba en el argumento de que las partes podían negociar en el contrato cualquier evento que podría eximirles del cumplimiento.

${ }^{34}$ Sobre este argumento, cfr. fallos Stubbs v. Holywel Railway Co. y Robinson v. Davison. ${ }^{35}$ Especialmente aplicable cuando el deudor debe satisfacer una prestación esencialmente diferente a la pactada.
} 
Evocando el mismo razonamiento que en Taylor v. Caldwell, no se conminó al pago del saldo, por cuanto era entendible que, para ambas partes era conocido que el motivo del contrato era la realización de los eventos de coronación; al respecto Garaventa y Manin (2012) señalan que la relevancia del caso fue la interpretación de que no era necesario que la condición fuera expresa en el documento contractual para que sea un elemento esencial del contrato, si se logra probar que dicha condición corresponde al fin del contrato $^{36}$. El elemento probatorio esencial para determinar que la consideration o fin del contrato fue el evento de la coronación consistió en la publicidad del mismo incluida en el anuncio de arriendo.

A partir de lo señalado «la teoría de la frustration inglesa genera una ruptura (discharge) automática del contrato, incluso contra la voluntad de las partes, que no podrían continuar la ejecución si el negocio fue declarado frustrado por los jueces» (Freytes, 2011, pp. 123-124). Las partes, por lo tanto, solo deben cumplir con las obligaciones exigibles previamente al hecho que frustra el contrato, por concepto de derechos adquiridos (Stone, 2005).

En la doctrina inglesa no se aplica la teoría de la frustración de fin del contrato cuando no existe ajenidad del hecho que lo frustra; o cuando éste no es la base del negocio (Beatson, Burrows \& Cartwright, 2016).

La figura se regula también en el ordenamiento estadounidense y se contrasta con la impracticability o impossibility ${ }^{37}$, por cuanto en esta última no se puede cumplir con la obligación por ser imposible fácticamente, mientras que en la frustración las obligaciones pueden cumplirse pero resultan inútiles porque se ha afectado la base del negocio jurídico (Chamie, 2010). La regla general además señala que si el deudor asumió la obligación en la distribución de riesgos del contrato, a pesar de frustración del mismo, debe responder. El Uniform Commercial Code también admite la figura en el art. 201 de la sección primera como medida excepcional cuando puede

\footnotetext{
${ }^{36}$ En el mismo conjunto de casos de la coronación destacan también Chandler v. Webster, en el que el objeto del contrato fue el alquiler de una habitación para mirar el evento, pero en este caso se hizo un pago adelantado de casi la totalidad de la renta. El inquilino demandó la devolución y el arrendador reconvino por el saldo, resolviéndose a favor del segundo, bajo el razonamiento de que el contrato ya se había perfeccionado antes de la cancelación y la figura de la frustración no declara la nulidad del contrato, sino que evita el cumplimiento de las obligaciones pendientes luego del caso fortuito que frustró el fin del contrato. Este precedente fue criticado por reputarse injusto y modificado legalmente con el Law Reform de 1943.

${ }^{37}$ La sección 265 del Restatement of Contracts se refiere a la ruptura de una asunción fundamental del negocio jurídico, ruptura ajena al deudor, lo cual descarga a dicha parte del cumplimiento. Para efectos prácticos permite la resolución y evitar el cumplimiento de obligaciones posteriores al hecho que frustra el contrato.
} 
comprobarse que el hecho es ajeno al deudor, imprevisible y que la destrucción de la base del contrato lo convierte en inútil. El efecto, por lo tanto es el discharge, por lo que el deudor se exime de la responsabilidad y el cumplimiento de las obligaciones posteriores al evento frustrante.

Tanto en el ordenamiento jurídico inglés como estadounidense la aparición de la teoría de la frustración es limitada y se entiende como una medida de ultima ratio, con el fin de que no sea utilizada frente a la mera dificultad en el cumplimiento, el fundamento final descansa en la justicia contractual y la buena fe objetiva.

Para el derecho continental es fundamental la obra referente a la base del negocio jurídico iniciada con la teoría de la presuposición de Bernhard Windscheid (Markesinis, Unberath \& Johnston, 2006), que intuyó la existencia de que había algo más allá de lo representado en el contrato, a lo que llamó presuposición (Voraussetzung). La presunción es, según el autor, una expectativa o creencia, sin la cual, quien emite una declaración de voluntad desistiría de ella. Se puede encuadrar a la presuposición como una condición no completamente desarrollada, un intermedio entre el simple motivo y la condición.

La subjetividad de la noción de Windscheid tuvo amplia crítica. Paul Oertmann, en un terreno más fértil a la reconsideración de la posibilidad de contradecir el principio de pacta sunt servanda generado por la incerteza que trajo consigo la Segunda Guerra Mundial señaló que la base del negocio es la representación mental de una de las partes concluido éste, comunicada a la contraparte y aceptada (Markesinis, Unberath \& Johnston, 2006, p. 322). También se incluye la común representación de las partes sobre la existencia o aparición de circunstancias. Este último punto permitía superar la crítica hecha a Windscheid, por cuanto la ruptura a la base del negocio que faculta a la resolución es aceptada por las dos partes. Respecto de esta teoría se mantiene la crítica relativa al subjetivismo y el sentido artificial de un supuesto consenso de las partes sobre la base del negocio.

Finalmente sería Karl Larenz quien comulgó la visión subjetiva y objetiva de la base del negocio jurídico. La base subjetiva se identifica con la representación mental de los contratantes al momento de concluir el negocio y que influido en las partes para la definición del contenido del contrato. La base subjetiva representa la presuposición de unas circunstancias presentes al momento de contratar o pasadas y la expectativa de que se mantengan en el futuro; el error de una de las partes respecto a la suposición y el aprovechamiento desleal del mismo por la otra es lo que faculta al deudor a solicitar el remedio, bajo el fundamento final de la buena fe como principio central (Larenz, 2002). Por su parte, la dimensión objetiva es un estado general de las cosas cuya existencia dota de sentido al negocio 
realizado y el contenido mismo del contrato. La dimensión objetiva del negocio jurídico se afecta por ruptura grave en la equivalencia de las prestaciones mutuas; o porque el fin objetivo del contrato es imposible a pesar de que las partes cumplan sus obligaciones (Larenz, 2002). Desde la perspectiva de lo expuesto en el presente trabajo, la teoría de la imprevisión se haría cargo del primer caso (equivalencia de las prestaciones) y la frustración del fin del contrato del segundo (inutilidad sobrevenida del contrato).

La teoría mixta de Larenz comprende que el contrato y su contenido responden a una realidad objetiva correspondiente al momento en que se celebra; así como, a una representación mental conjunta de las partes respecto de cómo debe desarrollarse la ejecución y el resultado esperado, para lo cual se intenta precautelar que existan soluciones frente a variaciones que puedan afectar gravemente al mismo. Se pueden verificar en la teoría de la base del negocio jurídico de Larenz los casos de error común, frustración de las expectativas razonables de las partes, la ruptura de la equivalencia de las prestaciones, equiparable a la teoría de la imprevisión; y, la pérdida de la finalidad del contrato que abarcaría la frustración de su fin (Gallo, 1992).

La influencia de la frustration del Common Law y el tratamiento de la misma desde la teoría de la base del negocio jurídico de Larenz ha influido especialmente la legislación civil de Europa Occidental de posguerra ${ }^{38}$.

Finalmente, en el contexto regional, Argentina ha acogido la institución de la frustración de la finalidad del contrato en el art. 1090 del Código Civil y Comercial de la Nación autorizando a la parte afectada a declarar la resolución del contrato ante la alteración extraordinaria de las circunstancias existentes al tiempo de su celebración, ajena a las partes y que supera sus riesgos asumidos. El remedio, la resolución, surte efecto con la notificación por la parte afectada a la otra.

La norma regula además la frustración temporal de la finalidad del contrato, ante la cual, la parte afectada puede solicitar la resolución

\footnotetext{
${ }^{38}$ El BGB (Bürgerliches Gesetzbuch) alemán introdujo en sus reformas de 2002 y 2009 normativa relacionada con la revisión contractual y la modificación de la base del negocio jurídico. En la sección 313, en el que se señala la adaptación como efecto del cambio significativo de las circunstancias bajo las que se celebró el contrato. Se equipara también al caso anterior cuando se han perdido las concepciones materiales del mismo. Si no se puede adaptar el contrato se prevé el derecho de revocación de la parte afectada; o de rescisión, en el caso de contratos de tracto sucesivo. El art. 6:258 lit. a) del Código Civil holandés de 1992 regula las circunstancias imprevistas y faculta al juez a revisar el contrato o resolverlo total o parcialmente si las mismas son de tal magnitud una de las partes no pueda continuar con el acuerdo sin dicha intervención. La resolución o revisión del contrato tendrá efectos retroactivos, lo que convierte a la norma holandesa en una de las más amplias sobre el tema.
} 
únicamente si impide el cumplimiento oportuno de una obligación en la que el tiempo de ejecución es esencial ${ }^{39}$.

El derecho de unificación de contratos también ha acogido la frustración del fin del contrato, el art. 6.2.2 de los Principios Unidroit regula la definición de hardship incluyendo la excesiva onerosidad sobreviniente como el caso en el que el valor del cumplimiento de la prestación que una parte recibe se ve disminuido. Para ambos casos. Los requisitos que se señalan en este artículo son que el hecho definido como hardship ocurra o llegue a saberse después de suscrito el contrato por la parte en desventaja, no hayan podido ser razonablemente previstos, estén fuera del control de ésta; $y$, su riesgo no haya sido asumido por la parte en desventaja ${ }^{40}$. Se regula con la misma redacción en el art. 1:110 del Draft Common Frame of reference of European Contract Law.

Los Principios Latinoamericanos de Derecho de los Contratos acogieron también la figura bajo la denominación de la frustración de la causa del contrato, en la norma que se refiere a la disminución significativa de la utilidad contenida en el art. $85^{41}$. La frustración definitiva de la causa del contrato por un cambio de las circunstancias existentes al momento de contratar permitiría resolverlo según esta norma. La función de la causa a la que se refiere el art. 85 de los Principios Latinoamericanos de Derecho de

\footnotetext{
${ }^{39}$ Esta norma tiene una larga trayectoria de discusión que se remonta a la IV Jornadas Bonaerenses de Derecho Civil, Comercial, en 1990, de la que se extrajeron como conclusiones que la frustración de la finalidad del contrato constituye una causal de extinción si se cumplen los requisitos de su existencia. En las XIII Jornadas Nacionales de Derecho Civil en 1991, por su parte se determinó que este instituto es autónomo; radica en un hecho sobreviniente imprevisible, ajeno a las partes, no generado cuando una de ellas esté en mora y que afecta la finalidad del contrato provocando el desinterés o inutilidad de su existencia (Freytes, 2011, pp. 134-136).

${ }^{40}$ En los comentarios del art. se incluye expresamente a la frustración de la finalidad del contrato como uno de los presupuestos abarcados por el mismo, se señala
}

«(..) or the frustration of the purpose for which the performance was required (e.g. the effect of a prohibition to build on a plot of land acquired for building purposes or the effect of an export embargo on goods acquired with a view to their subsequent export)».

${ }^{41}$ Según afirma Pizarro (2017), en la presentación de los Principios Latinoamericanos de Derecho de los Contratos, una de las justificaciones de la conservación de la causa como elemento del contrato está en que "permite anular un contrato cuando aquella se frustra en caso de alteración de las circunstancias existentes al momento de contratar o para acoger la teoría de la imprevisión. El fundamento es la causa de la obligación" (p.90). Se señala además la influencia directa del art. 1090 del Código Civil y Comercial de la Nación Argentina. Según San Miguel (2017), la noción confusa de la causa podría haberse omitido y llamar la figura "frustración del fin del contrato". 
los Contratos se equipara a las dimensiones subjetiva y objetiva de la base del negocio jurídico de Larenz, por cuanto se refiere al propósito perseguido por ambas partes en el contrato, o por una de ellas y que sea conocida por la otra. La motivación para la resolución radica en que el contrato sobrevino en inútil para la parte afectada. Las características de la circunstancia que provoca la frustración del fin del contrato son la imprevisibilidad, ajenidad, que modifiquen sustancialmente las circunstancias bajo las que el contrato se celebró; y que la misma no haya sido asumida por la parte afectada en la distribución de riesgos (San Miguel, 2017).

El remedio que los PLDC plantean para este caso coincide con los otros instrumentos de unificación y es la resolución, que parece operar sin intervención judicial, según lo regulado, en similar procedimiento que la resolución por incumplimiento del art. 98 que opera por simple comunicación.

Esta breve revisión de la teoría de la imprevisión y la frustración del fin del contrato nos permiten visualizar soluciones frente a la modificación de las circunstancias sobre las que se fundó el contrato, por un caso fortuito. Si se observa el devenir histórico de estas figuras se confirmará su recurrencia en casos de guerra, desastre o emergencias; y, a nuestro criterio, tienen justamente el efecto contrario a contravenir el principio de pacta sunt servanda, es decir, buscan que el contrato prevalezca.

\section{LEGISLAR DESDE LA EMERGENCIA Y RETORNO A LOS PRINCIPIOS}

El 12 de abril de 2020 se sugería en Chile la creación de una ley específica para efectos de la pandemia (Zúñiga \& Chaparro, 2020); el llamado se inspiraba en la experiencia europea; pero además en la insuficiencia del Derecho Común para cubrir la serie de eventos que puedan presentarse. La confrontación doctrinaria se configuró entre quienes abogaban el análisis caso a caso bajo el ordenamiento jurídico vigente y aquellos que abogaban por una Ley ad-hoc que establezca regulaciones expresas para casos concretos frente a la emergencia.

En el caso chileno no ha habido pronunciamiento del legislador más que en el ámbito laboral ${ }^{42}$, aspectos relacionados con los derechos del

\footnotetext{
42 Respecto a normativa relacionada con la emergencia sanitaria se han dictado la Ley 21.227 de 6-IV-2020 que faculta al acceso a prestaciones del Seguro de Desempleo de la Ley 19.728, en circunstancias excepcionales y su modificación a través de la Ley 21.232 de 1-VI-2020; Ley 21.218 de 3-IV sobre el subsidio para alcanzar un ingreso mínimo garantizado a trabajadores; Ley 21.220 de 26-III que modifica el Código de Trabajo
} 
consumidor $^{43}$, más no se ha abarcado la materia de contratos civiles (De la Maza \& Vidal, 2020) ${ }^{44}$. Recientemente se reguló la prohibición de corte de servicios básicos y posibilidad de postergación del pago bajo ciertas condiciones en Ley 21.249 de 8 de agosto de 2020 que sería la única norma de excepcionalidad en materia de contratación no laboral que se ha dictado durante la emergencia sanitaria.

Dentro de los proyectos de ley que se han presentado en los últimos meses el Boletín 13474-07 de 5 de mayo de 2020 contiene el Proyecto de Ley para dar reconocimiento positivo a la imprevisión en el Código Civil. Este texto alude a los fallos de la Corte de Apelaciones de Santiago ${ }^{45}$ que habrían aceptado la teoría y se menciona reiteradamente la regulación en derecho comparado, a su vez, derivada de los principios de buena fe y confianza legítima. El texto que se propone introduciría un art. 1546 bis en el Código Civil muy similar al 1195 del Código Civil francés.

respecto al trabajo a distancia; Ley 21.252 de 8-VIII-2020 que establece un financiamiento con aporte fiscal para la protección de los ingresos de la clase media; Ley 21.248 de 31 VII-2020 que contiene la reforma constitucional que permite el retiro excepcional de los fondos acumulados de capitalización individual según se indica; Ley 21.247 de 31-VII2020 que establece beneficios a los padres o madres que estén haciendo uso del permiso postnatal parental o que tengan el cuidado personal de niños o niñas nacidos a contar del año 2013, con motivo de la pandemia originada por la enfermedad denominada Covid-19; Ley 21.249 de 8-VIII-2020 que suspende el corte de servicios básicos por no pago en virtud de la crisis originada por el coronavirus; Ley 21.256 de 2-IX-2020 que establece medidas tributarias que forman parte del plan de emergencia para la reactivación económica y del empleo.

${ }^{43}$ Resolución Exenta 326 sobre contratación a distancia; Resolución Exenta 340 sobre suspensión de plazos de las garantías legales, voluntarias y de satisfacción; Resolución Exenta sobre sobre buenas prácticas de los proveedores frente a la pandemia; y, Resolución Exenta 371 sobre sobre resguardo de la salud de los consumidores y de medidas alternativas de cumplimiento, suspensión y extinción de las prestaciones frente a la pandemia provocada por el Coronavirus. Sobre la suspensión del plazo de la garantía legal se recomienda revisar (Isler, 2020).

${ }^{44}$ Cobro de aranceles en contratos de educación (Boletín 13508-04 cobro de aranceles según créditos tomados, 13482-04 equidad digital de los estudiantes, 13466-04 revisión de valores de matrículas y colegiaturas, 13445-04 baja de arancel anual por alumno, 13378-04 suspensión de cobro de aranceles y derechos de matrícula en educación superior); postergación del pago de cuotas de créditos hipotecarios o de consumo (Boletín 13454-03 para casos de vulnerabilidad, 13425-03 suspensión temporal, 13423-03 suspensión por seis meses de créditos, 13394-03 suspensión de créditos y prohibición de embargos, 13392-03, 13391-03, 13371-03 modifica Ley 19.496 para permitir refinanciamiento y postergación de pago de cuotas de créditos, 13.328 suspensión de pago de deudas hipotecarias).

45 Corte de Apelaciones de Santiago, Rol 6812-2001 de 14-XI-2006 y Rol 2187-2010 de 22-IX-2011. 
El boletín 13373-03 de 25 de marzo de 2020 contiene un proyecto de Ley que propone prohibir el aumento de precios de arriendo de locales habitacionales y, en el caso de pequeñas y medianas empresas (pymes), los comerciales; suspensión de pagos de arrendamiento para primer quintil, pensionados y pymes; y, suspensión de desalojos ${ }^{46}$. Por su parte, el boletín 13367-07 de 27 de marzo de 2020 se refiere a una modificación en la Ley de Arrendamiento de Predios Urbanos ${ }^{47}$. Ambos proyectos de ley proponen la suspensión de las obligaciones del arrendatario con pago prorrateado de los cánones suspendidos, una vez que se levante la medida, en el primer caso el fundamento parecería encajarse en la teoría de la imprevisión y configura la suspensión como una modalidad de revisión contractual, sin que se verifique que la obligación devenga en excesivamente onerosa para el arrendatario, aunque sí podría alegarse una disminución considerable de la utilidad del contrato, presupuesto concatenado a la teoría de la frustración del contrato. En el segundo caso, por el contrario, se señala expresamente al caso fortuito como causal para interponer una excepción ante la instauración de un proceso en virtud del Título III de la Ley 18.101 y del Título VI del Libro III del Código de Procedimiento Civil.

Las soluciones que han emanado desde la doctrina chilena para el problema del contrato de arrendamiento comercial se han inclinado por el razonamiento de que el acto de autoridad que impide al arrendatario gozar del inmueble arrendado para ejercer su actividad comercial se configura como un incumplimiento objetivo de la obligación contenida en el numeral segundo del art. 1924 del Código Civil, por parte del arrendador, lo que permitiría al arrendatario aplicar el inciso segundo del art. 1926, es decir, podrá desistir del contrato, quedándole a salvo la indemnización de perjuicios, siempre que el retardo no provenga de fuerza mayor o caso fortuito (De la Maza \& Vidal, 2020, pp. 144-145). Se presenta la aplicación de la excepción de contrato no cumplido (p. 145) en el caso de que el incumplimiento del arrendador sea solo temporal y exista motivo de las partes para conservar el contrato, una vez terminada la contingencia. El efecto en este segundo caso sería la suspensión de la cancelación del canon

\footnotetext{
${ }^{46}$ El fundamento señalado en el proyecto es "la pérdida de las condiciones objetivas que llevaron a las personas a contraer obligaciones contractuales relacionadas a arriendo de inmuebles". Las suspensiones operan a petición del arrendatario y los valores no pagados pueden prorratearse hasta en los 12 meses posteriores a la declaración de emergencia.

${ }^{47}$ Este proyecto faculta a quien tiene calidad de arrendatario o demandado pueda interponer una excepción por causal de fuerza mayor, hasta dentro de los 30 días posteriores al establecimiento de un acto de autoridad que restrinja la movilidad en caso de declaración de catástrofe. Se exige acreditación de la imposibilidad de pago. La aceptación de la causal no libera del pago al deudor.
} 
arrendaticio por el tiempo del impedimento. Finalmente puede darse el caso de impedimento parcial, para lo que se plantea otro remedio, también presente en todos los instrumentos de unificación del derecho de contratos, como es la reducción del precio (p. 146). Otra parte de la doctrina ha interpretado la afectación del Covid-19 al contrato de arrendamiento de local comercial bajo los presupuestos de la frustración del fin del contrato, rechazando que exista un incumplimiento por parte del arrendador; por lo que, el caso fortuito provoca una pérdida de la utilidad del contrato, especialmente por la dificultad que reportará el arrendatario para seguir cumpliendo con el pago del canon, aun después del acto de autoridad, en razón de la disminución de la actividad comercial (Momberg, 2020).

Respecto al contrato de arrendamiento de vivienda poco ofrece el Derecho Común, al ser una obligación dineraria del arrendatario, por lo que su incumplimiento es culpable (Momberg, 2020; De la Maza y Vidal 2020, p. 143); en este punto surge como idea una noción novedosa como la fuerza mayor social (Goldenberg, 2020) o la identificación de los inquilino como contratante vulnerables con un trasfondo del derecho social a la vivienda.

En el derecho comparado se observa en Alemania a la Ley No.14 de 27 de marzo de $2020^{48}$ que reformó la Ley introductoria al BGB, estableciendo en la sección 1 de su art. 40 la facultad para suspender hasta el 30 de junio del presente aquellos contratos que contengan obligaciones esenciales de ejecución continuada y que no puedan ser cumplidas por motivo de la emergencia; la misma facultad se otorga a las pequeñas y medianas empresas. El término obligaciones esenciales es entendido en sentido amplio e incluye arriendo, pago de servicios básicos, entre otros (Lehmann, 2020). El límite a esta facultad es que el acreedor se vea comprometido en su sustento. Se prohíbe además la terminación de los contratos de arrendamiento, temporalmente. No se prevé el pago diferido posterior de las cuotas no canceladas; por lo que, traducido a lenguaje de principios, podríamos encasillar esta norma en una maximización de los deberes de cooperación entre las partes, optándose por la conservación del contrato a través del sacrificio económico mutuo y razonable.

En España, el Real Decreto Ley 11/2020 de 31 de marzo se hace cargo del arrendamiento de locales para vivienda a través de la suspensión de los procesos de lanzamiento y desahucio, para lo cual el arrendatario debe acreditar que se encuentra en situación de vulnerabilidad ${ }^{49}$; sin embargo el

\footnotetext{
${ }^{48}$ Ley 14 para mitigar las consecuencias de la pandemia Covid-19 en el derecho civil, quiebra y procesal penal, 27-III-2020.

${ }^{49}$ Los arts. 3 y 4 se dedican a definir los requisitos de la situación de vulnerabilidad del arrendatario y la manera de acreditarlos. La rigurosidad de estos requisitos para solicitar las
} 
arrendador también puede postular a medidas de apoyo si recae en igual situación. En segundo lugar, se regula la posibilidad de que, previa solicitud del arrendatario, se aplique

«una prórroga extraordinaria del plazo del contrato de arrendamiento por un periodo máximo de seis meses, durante los cuales se seguirán aplicando los términos y condiciones establecidos para el contrato en vigor. Esta solicitud de prórroga extraordinaria deberá ser aceptada por el arrendador, salvo que se fijen otros términos o condiciones por acuerdo entre las partes».

Los arts. 3 y 4 regulan una mora de la deuda arrendaticia, que además es obligatoria y automática en el caso de arrendadores que sean grandes tenedores o una empresa o entidad pública de vivienda, recurriendo entonces, como en el caso alemán, a la identificación del contratante fuerte con mayores posibilidades de resistir los efectos de la pandemia ${ }^{50}$.

El Real Decreto Ley 15/2020 regula la renta de locales comerciales y la renta industrial. El preámbulo de la norma acusa que la Ley de Arrendamientos Urbanos

«(...) no prevé causa alguna de exclusión del pago de la renta por fuerza mayor o por declaración de estado de alarma u otras causas, salvo en lo referido en su artículo 26, relativo a la habitabilidad de la vivienda derivada de la ejecución de obras $(\ldots) \gg$.

Lo mismo hace con el Código Civil que solo prevé la resolución; por lo que, se alinea inmediatamente con la necesidad de una regulación en línea con la cláusula rebus sic stantibus y evoca su aceptación jurisprudencial por el Tribunal Supremo.

La fórmula propuesta para este caso en el art. 1, num. 1, del Real Decreto es la moratoria automática para el arrendatario, cuando el arrendador es empresa o entidad pública de vivienda o gran tenedor por el periodo de tiempo que dure el estado de alarma y sus prórrogas y a las mensualidades siguientes, prorrogables una a una, sin que puedan superarse,

medidas y la dependencia de la solución de la aceptación del arrendador provocan que muchas relaciones contractuales de arriendo no estén reguladas, o que no exista solución cuando el arrendador no acepta la medida (García, 2020).

${ }^{50}$ Cuando arrendador y arrendatario no lleguen a un acuerdo de moratoria, el Decreto Ley ofrece un remedio de reducción de precio del $50 \%$ por el tiempo del estado de alarma; o, una moratoria por el tiempo que dure el mismo y posterior aplazamiento con prorrateo hasta por tres años. El arrendatario no sufrirá penalización ni cobro de intereses por los montos aplazados. En todo caso, quedan pendientes de regulación los casos en que las partes pacten remedios más gravosos que el establecido en la Ley o la concurrencia de vulnerabilidades de arrendador y arrendatario (García, 2020, p. 22). 
en ningún caso, los cuatro meses. El pago se aplaza y es fraccionable a dos años sin cobro de intereses ni penalización. Al igual que en el caso de vivienda, se apela en primer lugar al acuerdo y cooperación de las partes, pero de no producirse, se provoca legalmente una renegociación con aplazamiento de los cánones no pagados y prorrateo de sus pagos. Para la aplicación de esta figura resulta esencial la identificación del caso en que el arrendador puede resistir la medida, al que se denomina gran tenedor. Efectivamente, lo que opera en el caso español se asimilaría a la aplicación de la teoría de la imprevisión, sustentada en la aceptación jurisprudencial, con claros límites de orden público establecidos en la Ley que establece características para identificar un contratante fuerte y uno débil. En el caso de que el arrendador no tenga las características de gran tenedor, se conmina a los deberes de cooperación de las partes para lograr un aplazamiento extraordinario en el pago o reducción del canon arrendaticio; así como, la imputación de los montos consignados como fianza al pago. A una parte de la doctrina esta solución le ha parecido más gravosa que la del derecho común, por cuanto, a su parecer, éste permitía la resolución o suspensión por incumplimiento del acreedor, mas no un aplazamiento, al estar impedido de proporcionar el uso de la cosa (García, 2020).

En el caso de Portugal el art. 437 del Código Civil regula la alteración del contrato por circunstancias sobrevinientes; mientras que el 252 el error en el motivo, y la frustración del fin del contrato; sin embargo, se ha visto en la necesidad de expedir una norma ad-hoc ante la insuficiencia de estas instituciones (Pinto, 2020). En materia de arrendamiento se promulgó la Ley 4-C/2020 de 6 de abril. Las medidas a las que se accede con el cumplimiento de uno de los requisitos que lo identifiquen como parte vulnerable ${ }^{51}$ son, en primer lugar, acceso a un crédito sin intereses otorgado por el Estado; y, de manera complementaria, se exime al arrendatario el pago de una indemnización del 10\% del canon prevista en el art. 1041 num. 1 del Código Civil y ni se podrá resolver el contrato por parte del arrendador, ante el no pago de las cuotas durante la emergencia y hasta un mes después. El arrendador solo podrá resolver el contrato si, una vez pasada la emergencia y hasta el primer posterior a la misma, el inquilino no hace su pago, dentro de los 12 meses posteriores al final de ese período, en cuotas mensuales de no menos de una doceava parte del monto total, pagado junto con el alquiler

\footnotetext{
${ }^{51}$ Los requisitos para acceder a la medida se identifican, al igual que los casos anteriores, con la vulnerabilidad; debe haber una quiebra del $20 \%$ de los rendimientos de la unidad familiar del arrendatario frente a los del mes anterior o el período homólogo del año anterior. El rendimiento de todos los esfuerzos de dicha unidad, para el pago de arrendamiento, sea o supere el $35 \%$.
} 
de cada mes. Por lo tanto, emulando el caso español, respecto a arriendo habitacionales, la fórmula es una prórroga, fundamentada en la vulnerabilidad, respondiendo a una renegociación del contrato con fundamento legal, aplicada de forma subsidiaria si las partes no llegaron inicialmente a un acuerdo.

En el caso de arrendamiento no habitacional se invierte la prioridad de las medidas frente al caso anterior, estableciéndose en primer lugar la opción de postergación, suspendiéndose el pago mientras esté en vigor la emergencia y hasta un mes después, teniendo que pagar los cánones prorrateados en los doce meses posteriores; al igual que en el caso de vivienda se suspende el derecho del arrendador a terminar el contrato o cobrar la indemnización por incumplimiento.

Una protección final al arrendatario de vivienda contenida en el art. 7 de la Ley 4-A/2020 de 6 de abril suspende, durante la medida de emergencia y hasta 60 días después de la misma, los efectos de la caducidad, revocación, denuncia y oposición a la renovación del contrato por parte del arrendador.

En Francia, el art. 4 de la Ordonnance 2020-316 de 25 de marzo de 2020 señala que, las personas mencionadas en el art. 1 no pueden incurrir en multas financieras o intereses por demora, daños, penalidades, ejecución de cláusula de rescisión, cláusula penal o cualquier cláusula que prevea la confiscación o activación garantías o garantías, debido a la falta de pago de alquileres o cargos de alquiler relacionados con sus locales profesionales y comerciales, a pesar de cualquier estipulación contractual y las disposiciones de los arts. L. 622-14 y L. 641-12 del Código de Comercio. Esas personas son aquellas físicas o jurídicas que ejerzan una actividad económica que pueda beneficiarse del fondo de solidaridad regulado en la Ordonnance 2020-317 de 25 de marzo de 2020. Se repite el requisito de la identificación del contratante vulnerable para acceder a las medidas especiales y exoneraciones. En el caso francés, aparentemente, el tema contractual se ha dejado a cuidado del derecho común, por cuanto el art. 1195 del Código Civil de 2016 regula la teoría de la imprevisión (Pazos, 2020).

Ya en nuestra región resalta el caso colombiano en el que, como se señaló, se regula la teoría de la imprevisión en el art. 868 del Código de Comercio, pero, prácticamente, no aparece en la jurisprudencia (Vargas, 2020). En Colombia se optó también por una normativa ad-hoc contenida en el Decreto 579 de 15 de abril de 2020 en materia de arrendamiento. En el art. 1 se suspenden desde la vigencia del Decreto, hasta el 30 de junio de 2020 cualquier orden de desalojo por orden judicial o administrativa que tenga como fin la restitución de inmuebles habitados por arrendatarios, sin excepción. Se suspende hasta la misma fecha cualquier reajuste de canon de 
arriendo y se señala que finalizado el periodo de emergencia se incluirá en los pagos mensuales los incrementos no cobrados.

Al igual que en las normas anteriormente analizadas, el art. 3 del Decreto apela a la posibilidad de acuerdo de las partes, lo que facultaría por disposición legal a la renegociación sin que medie incumplimiento (rebus sic stantibus); de no lograrse el acuerdo, se prohíbe el cobro de interés por mora o penalidades y se faculta al pago del $50 \%$ de intereses corrientes.

Adicionalmente se prevé una prórroga de los contratos que hubieran podido terminarse en el periodo de vigencia de la emergencia, hasta el 30 de junio de 2020.

Por lo señalado, esta norma es mucho menos interventora que las europeas, prohibiendo el desahucio, sin señalar nada sobre la terminación y actuando sobre intereses o multas, mas no aplica moratoria o prórroga al canon de arrendamiento, apenas liberaría al arrendatario de probar el caso fortuito o fuerza mayor para eximirse del pago de indemnización, por lo que la norma no resuelve el posible advenimiento de un gran número de terminaciones de contrato por incumplimiento (Vargas, 2020, p. 153). Aplica la misma normativa a locales comerciales. El ejemplo colombiano puede ser una muestra de cómo la afectación al principio de permanencia del contrato puede agravarse por la ausencia de regulación de la capacidad de renegociación o terminación por frustración del fin del contrato sumado a una norma ad hoc que tampoco brinda soluciones; habrá que ver cómo se producen los efectos de lo actuado.

Finalmente, otro caso que demanda atención es el ecuatoriano, por cuanto ha sido uno de los países más afectados por Covid-19 y carece también de regulación de la teoría de la imprevisión o la frustración del contrato en su Código Civil ${ }^{52}$ o incluso en el recientemente promulgado Código de Comercio de 2019. El 16 de abril de 2020 el Presidente remitió el Proyecto de Ley Orgánica de Apoyo Humanitario para combatir la crisis sanitaria derivada del Covid-19. Este proyecto se convirtió en Ley publicada en el Suplemento del Registro Oficial 229 del 22 de junio de 2020. En lo referente a contratos de arrendamiento, el art. 4, emulando a los casos reseñados de España, Portugal y Colombia, prohíbe la ejecución de desahucio de arrendatarios de bienes inmuebles por cualquiera de las causales establecidas en el art. 3 de la Ley de Inquilinato durante el tiempo de permanencia de la emergencia y hasta sesenta días después. Las únicas excepciones a la prohibición de desahucio son la ruina del edificio o su uso

\footnotetext{
${ }^{52}$ El art. 1574 inciso segundo del Código Civil ecuatoriano, sin embargo, señala que si la mora en el cumplimiento obedece a un caso fortuito o fuerza mayor, el deudor no está obligado a pagar daños y perjuicios.
} 
para actividades ilegales ${ }^{53}$. El arrendatario, para acogerse a la suspensión temporal de desahucio, debe cancelar el $20 \%$ de valores adeudados en caso de arriendo de vivienda; en el caso de locales comerciales, adicionalmente el arrendatario debe acreditar una reducción de ingresos del $30 \%$ respecto del mes anterior para poder solicitar el beneficio ${ }^{54}$. Se apela a la autonomía de las partes y capacidad de renegociación de las condiciones del contrato al facultarles extender el periodo de suspensión del desahucio tras el acuerdo por escrito de un plan de pagos o, inclusive, que el arrendador exima al arrendatario del pago del canon, acuerdo que tendrá valor de título ejecutivo.

Se prevé entonces la posibilidad de prorrogar los cánones por acuerdo de las partes, pero de no existir éste, la obligación del pago no se ve alterada, por lo que la norma suspende la facultad del arrendador de solicitar el desahucio por incumplimiento en el pago, pero no se hace cargo de la terminación del contrato. Finalmente se hace una distinción de aquellos contratantes vulnerables identificándolos como parte de alguno de los grupos de atención prioritaria que constan en la Constitución ${ }^{55}$ y el canon arrendaticio sea su medio de subsistencia, con el fin de que no proceda la suspensión del pago del canon de arrendamiento si el arrendador es el contratante vulnerable; si el arrendatario también lo es, se conmina al

\footnotetext{
${ }^{53}$ No se regula el caso en el que las causales de desahucio se hayan producido antes de la vigencia del Decreto que declara el estado de excepción, aunque aparentemente estarían incluidas en la suspensión y no podría solicitarse el desahucio, especialmente por el carácter protector de la norma respecto a la vivienda del inquilino, una interpretación en contrario desnaturalizaría el sentido tutelar del régimen especial creado. De todos modos, se considera que el régimen debe equilibrarse con medidas que no vulneren la situación económica de los arrendadores, más allá de lo previsto para contratantes vulnerables que, al final, recurre a la autonomía de la voluntad de las partes ara negociar un acuerdo. Reporta complicaciones la prohibición del desahucio inclusive frente a la causal por la que el arrendado requiere el inmueble para vivir, como consta en el literal i) del art. 30 de la Ley de Inquilinato, donde colisionaría el derecho a la vivienda del arrendador con el del inquilino, aparentemente la distribución de riesgos frente a la prohibición contenida en el Proyecto de Ley cargaría en ese caso al arrendador en exceso.

${ }^{54}$ Esto podría hacerse a través de la verificación de la facturación e información contable, como sucede en los casos de la norma española o portuguesa.

${ }^{55}$ Los grupos de atención prioritaria están señalados en el art. 35 de la Constitución de Ecuador que señala:
}

«Las personas adultas mayores, niñas, niños y adolescentes, mujeres embarazadas, personas con discapacidad, personas privadas de libertad y quienes adolezcan de enfermedades catastróficas o de alta complejidad, recibirán atención prioritaria y especializada en los ámbitos público y privado. La misma atención prioritaria recibirán las personas en situación de riesgo, las víctimas de violencia doméstica y sexual, maltrato infantil, desastres naturales o antropogénicos. El Estado prestará especial protección a las personas en condición de doble vulnerabilidad». 
acuerdo a las partes. Este apartado confunde la suspensión que obliga la norma, que es la de iniciar el desahucio por parte del arrendador con la de suspender los pagos de canon de arrendamiento, que no está incluida en la Ley y solo operaría por acuerdo de las partes; aparentemente, esta norma prohibiría que el arrendador vulnerable pueda acordar la remisión del pago del canon de arrendamiento con el arrendatario, lo que no reporta mucho sentido.

Como se puede observar, la norma procura que el arrendatario no pierda su vivienda o el lugar en que desempeña sus labores, sin embargo, deja totalmente a las partes la forma en que se pueda suspender la obligación del pago de la renta o su cumplimiento diferido. Por otro lado, la capacidad de renegociación concedida a las partes, dentro de los límites mínimos establecidos por el proyecto de ley, consolidaría la aplicación de la teoría de la imprevisión como solución elegida, por lo que, eventualmente, podría dar apertura a una revisión judicial del contrato en procura de su conservación.

\section{LECCIONES DEL COVID-19 ¿UN DERECHO DE CONTRATOS POR PRINCIPIOS?}

Como se puede observar, la normativa ad hoc apela a la posibilidad de renegociación de las condiciones de los contratos por las partes, partiendo de la premisa de que el acto de autoridad emanado, a partir de Covid-19, se configura como caso fortuito, al menos, mientras seguía siendo un hecho imprevisible.

¿Se pueden llegar a soluciones similares, entiéndase renegociación o resolución por frustración del fin del contrato, cuando las figuras no han sido acogidas por el derecho común ni introducidas por una ley ad hoc? Llegado el caso y bajo las circunstancias actuales, ¿podría un juez en Chile, ordenar reducción de precio, postergación del pago del canon de arriendo o moratorias si se le ha solicitado la adaptación contractual; o incluso, ¿resolver el contrato que ya no reporte utilidad a las partes?

Para responder esta interrogante se debe indagar sobre los fundamentos finales del derecho de contratos que se asienta en sus principios generales. Los principios, a diferencia de las reglas, constituyen mandatos de optimización que procuran ser cumplidos en lo máximo posible (Laporta, 1999), muestran la dirección en la que puede ofrecerse la solución a un conflicto; por ello, la colisión entre principios no se resuelve por exclusión de uno ellos sino por ponderación, el peso asignado a cada uno corresponde a la base axiológica bajo la cual son evaluados y ceden mutuamente hasta llegar a la solución más equitativa (Aarnio, 2000), por ende, tienen 
correspondencia con valores y se constituyen como racionalización de las reglas (MacCormick, 2019).

Este último razonamiento parece responder al caso que estamos tratando; en efecto, así como las reglas establecidas por el legislador se forman en base a la adhesión a principios políticos y morales presentes en el momento creativo de la norma (espíritu de la Ley); los principios jurídicos son tales, en la medida de su función justificativa real o potencial, respecto de las reglas establecidas en el derecho positivo, en base a criterios de reconocimiento (MacCormick, 2019).

Por lo señalado, un principio del derecho de contratos como la buena fe contractual, incorporado al Código Civil en el siglo XIX, inspirado en valores como la honestidad, honradez y rectitud que deben guardar quienes pactan y que en el contexto de su construcción tenía la finalidad de fortalecer la fuerza obligatoria de los contratos y la seguridad jurídica; en el contexto del siglo XXI, lleno de incertidumbres y aquejado por el desequilibrio de la posición de los contratantes ante el surgimiento de una emergencia extraordinaria y global, puede permitir a las mismas partes, o al juzgador, la revisión contractual; o, en su caso, la resolución del contrato sin que esté atada al incumplimiento culpable. Se ha afirmado inclusive que, lo que el juez hace al aplicar la buena fe es crear nuevas reglas que concretizan, integran o corrigen aquellas contenidas en la sistemática de la norma (Hesselink, 2011, 645).

La buena fe, desde su función integradora, parece ser el fundamento más adecuado de un deber de renegociación de las partes frente a la excesiva onerosidad sobreviniente en el cumplimiento de las obligaciones de una de ella, por motivo del advenimiento de un caso fortuito, Como señala Momberg (2010):

«En definitiva, los conceptos de ejecución de buena fe, cooperación, lealtad comercial y solidaridad contractual a los cuales se han hecho referencia en párrafos anteriores, no pueden considerarse extraños a nuestro derecho si lo consideramos desde una perspectiva contemporánea. Al efecto, se ha sostenido que la imposición a las partes de diversos deberes de conducta derivados del principio general de buena fe es el reflejo de una tendencia internacional hacia una mayor moralización de las relaciones contractuales, a la cual, según nuestra opinión, nuestro ordenamiento no puede permanecer ajeno» (p. 57).

La buena fe como principio general ejerce sus funciones informadora, interpretativa e integradora (Schopf, 2018). En Chile, se encuentra consagrada la buena fe como principio general de los contratos en el art. 1546 del Código Civil, la doctrina ha señalado que esta norma, por ejemplo, permite la protección de expectativas razonables emanadas del contrato 
(Eyzaguirre \& Rodríguez, 2013), incluso se han erigido otras figuras con cierta autonomía, aunque finalmente podrían formar parte de ella, como la confianza razonable (López, 2018) o la justicia contractual. En esta norma la buena fe aparece como sensatez o razonabilidad (San Martín, 2018) en la relación contractual, por lo que es fundamento de obligaciones contractuales que se deriven de su contenido abierto, siendo el deber de renegociación una de ellas.

Ahora bien, el problema de principios, finalmente ante un caso fortuito, como el que ha acaecido por la pandemia Covid-19, conlleva a la aparente colisión entre el pacta sunt servanda y el deber de renegociar o la facultad de resolver ante un inminente desequilibrio contractual producido por la ineficacia sobrevenida del contrato para una de las partes; ambas sustentados, finalmente, en la buena fe. Al ser principios, su colisión no implica la exclusión de uno frente al otro sino la correcta valoración de su alcance de aplicación dentro del caso concreto; por lo tanto, lo que los jueces están llamados a hacer en los meses y años subsiguientes, ante la falta de una regla específica establecida por el legislador; o, que existiendo ésta, no sea capaz de abarcar la multitud inimaginable de situaciones que la crisis sanitaria traerá consigo; será ponderar (De la Maza, 2014), y de dicha ponderación, se debe obtener un grado de satisfacción de los intereses de las partes, que a la final tienen un trasfondo en derechos.

El derecho por principios y la ponderación son comunes en el Derecho Constitucional $^{56}$, en el que los jueces deben hacerlo ante la colisión de derechos fundamentales que no tienen jerarquía entre sí y se consagran en forma de principios en las Constituciones. Parece ser que la emergencia sanitaria ha corroborado la necesidad de que el derecho de contratos tenga herramientas eficaces frente a la incertidumbre; si el derecho común genera mayor injusticia en caso de excepcionalidad, la búsqueda de la justicia permite que los jueces puedan encontrar en los principios y la equidad (Riofrío, 2020, pp. 10-11) instrumentos para alcanzar soluciones justas cuando las reglas son insuficientes, lo que se verá reflejado en la jurisprudencia de los años venideros.

\section{CONCLUSIONES}

1. La pandemia Covid-19 constituye caso fortuito de manera general, aunque no siempre es así. Si lo planteado es cierto, los actos de autoridad

\footnotetext{
${ }^{56}$ El debate es amplio y ha convocado a algunos de los juristas más importantes de las últimas décadas (Atienza, 2010; Alexy, 2009).
} 
emanados debido a la pandemia reúnen las características del caso fortuito, a saber, imprevisibilidad, externalidad e irresistibilidad. Sin embargo, hay que hacer dos precisiones; en primer lugar, la imprevisibilidad se justificó, a más tardar, cuando surgió un primer caso en el país, luego de lo cual, un contrato celebrado después de este hecho ya debería haber tomado en cuenta los efectos de medidas restrictivas. En segundo lugar, la irresistibilidad no se cumple en ciertos casos, como aquellos en que la implementación de una determinada modalidad permite el cumplimiento. Por otro lado, las obligaciones dinerarias, por su naturaleza, no pueden dejar de cumplirse; lo que no obsta que el caso fortuito provocado por Covid-19 dificulte su cumplimiento porque el deudor perdió o redujo su fuente de ingreso; sin embargo, la atención a este hecho responde más bien a una obligación estatal de política pública frente a la vulnerabilidad y facilitar herramientas para la renegociación o suspensión del cumplimiento de obligaciones.

2. La teoría de la imprevisión y la frustración del fin del contrato son figuras útiles frente a situaciones anormales, pueden convivir con el principio de pacta sunt servanda; $y$, de hecho, el efecto de la primera es la conservación del contrato mediante la renegociación; y de la segunda, su resolución para la prevención de efectos extremadamente injustos. Estas figuras son inherentes a la naturaleza falible de lo humano y deben ser parte del Derecho Común; sin embargo, si no constan como reglas expresas el juzgador o las partes pueden usarlas recurriendo a los principios de buena fe, justicia contractual y la equidad.

3. La legislación de emergencia ha procurado la renegociación y acuerdo de las partes; pero ha planteado, en los casos afortunados, límites de orden público motivados por la protección del contratante débil, procurando afectar lo menos posible a la seguridad de los pactos.

4. La reacción del derecho de contratos debe ser dúctil, como la realidad misma, entender el derecho de contratos por principios y a estos como racionalización de las reglas, puede ser fundamental para el reto inmediato de los juzgadores, especialmente sin normas a la medida, que, hasta el momento, serán quienes lideren la primera línea de la posible avalancha de incumplimientos judicializados; hay que ver que ni quienes cuentan con todas la herramientas en su derecho común se han despreocupado demasiado. 


\section{REFERENCIAS}

Aarnio, A. (2000). Reglas y principios en el razonamiento jurídico. Anuario da Facultade de Dereito da Universidade da Coruña, 4, 593-602. ISSN: 1138-039X. http://hdl.handle.net/2183/2070

Abeliuk, R. (2014). La Obligaciones, t. II, ed. 6. Santiago de Chile: Thomson Reuters.

Alcalde, E. (2007). Corte de Apelaciones de Santiago Y Teoría de la Imprevisión. Un hito fundamental en la evolución de nuestra justicia ordinaria: Guillermo Larraín Vial con Servicio de Vivienda y Urbanización de la Región Metropolitana. Corte de Apelaciones de Santiago 14 de noviembre de 2006. Revista chilena de derecho, 34(2), 361-372. https://dx.doi.org/10.4067/S071834372007000200008

Alexy, R. (2011). Los Derechos Fundamentales y el Principio de Proporcionalidad. Revista Española De Derecho Constitucional, 91, 11-29. En www.jstor.org/stable/24886085

All Answers Ltd. (2018). Krell v. Henry [1903]. En https://www.lawteacher.net/cases/krell-v-henry.php?vref=1

All Answers Ltd. (2018). Taylor v. Caldwell [1863] 3 B\&S 826 Case Summary. En https://www.lawteacher.net/cases/taylor-v-caldwell.php?vref=1

Atienza, M. (2010). A Vueltas con la Ponderación. Anales de la Cátedra Francisco Suárez, 44, 43-59-59. https://doi.org/10.30827/acfs.v44i0.498

Baraona, J. (1997). La exigibilidad de las obligaciones: noción y principales presupuestos (con especial énfasis en las cláusulas de aceleración). Revista Chilena de Derecho, 24(3), 503-523.

Barba, V. (2020). Las intervenciones del Legislador italiano en relación con los aspectos de Derecho civil para hacer frente a la emergencia del Covid-19. Revista de Derecho Civil, 7(2), 75-87.

Beatson, J., Burrows, A. S. \& Cartwright, J. (2016). Anson's Law of Contract. Reino Unido: Oxford University Press.

Brantt, M. (2009). La exigencia de exterioridad en el caso fortuito: su construcción a partir de la distribución de los riesgos del contrato. Revista de derecho (Valparaíso), (33), 39-102. https://dx.doi.org/10.4067/S071868512009000200001.

Brantt, M. (2010). El caso fortuito y su incidencia en el derecho de la responsabilidad civil contractual: Concepto y función del caso fortuito en el Código Civil Chileno. Santiago de Chile: Abeledo Perrot-Legal Publishing.

Brantt, M. (2011). El caso fortuito:concepto y función como límite de responsabilidad. En De la Maza, Íñigo (coord.) Incumplimiento contractual. Nuevas Perspectivas, (pp. 47-82). Santiago: Ediciones Universidad Diego Portales.

Brunner, C. (2008). Force Majeure and Hardship under General Contract Principles. La Haya, Holanda: Wolters Kluwer. 
Cabrillac, R. (2018). El nuevo derecho francés de las obligaciones. España, Barcelona: Cátedra Jean Monnet. http://diposit.ub.edu/dspace/bitstream/2445/126944/1/WP_2018_10.pdf

Cárdenas, H. \& Reveco, R. (2018). Remedios Contractuales. Santiago de Chile: Thomson Reuters.

Carrasco, A. (2020). Locales de negocio cerrados por COVID: la barbarie o el lobby hacen su agosto (segunda versión, reforzada para los incrédulos). Centro de Estudios de Consumo. Madrid, España.

Chamie, J. (2010). Frustration of Contract e Impossibility of Performance en el Common Law estadounidense. Revista De Derecho Privado, 18, 95-122. de https://revistas.uexternado.edu.co/index.php/derpri/article/view/404

Contardo, I. \& Cortez, H. (2019). Cuantificación del daño moral de los consumidores. Santiago, Chile: Ediciones DER.

Corral, H. (2007). La aplicación jurisprudencial de la buena fe objetiva en el ordenamiento civil chileno. Revista De Derecho Privado, 12-13, 143-178. https://revistas.uexternado.edu.co/index.php/derpri/article/view/563

Coustasse, A. (1958). Caso fortuito ante el Derecho Civil. Santiago de Chile: Ed. Jurídica de Chile.

De la Maza, I. \& Vidal, Á. (2020). El impacto del Covid-19 en los contratos. El caso chileno: Medidas excepcionales y Derecho. Revista de Derecho Civil, 7(2), 135-148.

De la Maza, I. (2014). La buena fe como dispositivo de ponderación. En A. Vidal y A. Morales Moreno (eds.), Estudios de Derecho de Contratos. Formación, cumplimiento e incumplimiento. Santiago de Chile: Thomson Reuters.

De la Maza, I. (2020, abril 3). El caso fortuito en los tiempos de coronavirus. El Mercurio Legal. En https://www.elmercurio.com/Legal/Noticias/AnalisisJuridico/2020/04/03/El-caso-fortuito-en-los-tiempos-del-coronavirus.aspx

Dörr, J. (1985). Notas acerca de la teoría de la imprevisión. Revista Chilena de Derecho, 12, 253-270. En https://repositorio.uc.cl/bitstream/handle/11534/11831/000306180.pdf?sequenc $\mathrm{e}=1$

Elorriaga, F. \& López, J. (2017). Los Contratos. Parte General. Santiago de Chile: Thomson Reuters. En https://proview.thomsonreuters.com/launchapp/title/LALEY/2017/42133709/v1

Eyzaguirre, C. \& Rodríguez, D. (2013). Expansión y Límites de la Buena Fe Objetiva - A Propósito del "Proyecto de Principios Latinoamericanos de Derecho de los Contratos". Revista chilena de derecho privado, 21, 137-216. https://dx.doi.org/10.4067/S0718-80722013000200005

Fang Lim, X., Chengfa, B., Pascoe, S., How, C., Chan, S. et. Al. (2019). Detection and characterization of a novel bat-borne coronavirus in Singapore using multiple molecular approaches. Journal of General Virology, 100, (10). https://doi.org/10.1099/jgv.0.001307 
Derecho de contratos y excepcionalidad: reaparición de instituciones y retorno a los...

Fernández, E. (2016). La alteración sobrevenida de las circunstancias contractuales y la doctrina rebus sic stantibus. Génesis y evolución de un principio jurídico. Persona y derecho. Revista de fundamentación de las Instituciones Jurídicas y de Derechos Humanos, 74, 291-318.

Freytes, A. (2010). La frustración del fin del contrato. Córdoba, Argentina: Ediciones de la Academia Nacional de Derecho y Ciencias Sociales de Córdoba.

Gallo, P. (1992). Sopravvenienza contrattuale e problemi di gestione del contratto. Milán: Giuffrè.

Garaventa, C. \& Manin, M. (2012). Sobre los orígenes de la doctrina de la frustración del fin del contrato. Comentario al fallo Krell v. Henry. Lecciones y Ensayos. 90, 312-324. En http://repositoriouba.sisbi.uba.ar/gsdl/collect/pderecho/lecciones/index/assoc/H WA_1038.dir/1038.PDF

García, M. P. (2020). Medidas en materia de contratos por el Covid-19 en España. Revista de Derecho Civil, 7(2), 15-46.

Goldenberg, J. (2020). A propósito del covid-19: incapacidad sobreviniente de pago y "fuerza mayor social". El Mercurio Legal. Santiago de Chile. En https://www.elmercurio.com/Legal/Noticias/Opinion/2020/04/27/A-propositodel-covid19-incapacidad-sobreviniente-de-pago-y-fuerza-mayor-social.aspx.

Grasso, M. (2019). Imprevisibilidad, contrato e imprevisión en el nuevo código civil y comercial argentino. Revista de Derecho Privado, 36, 93-125. https://doi.org/10.18601/01234366.n36.04.

Grupo de Estudio para un Código Civil Europeo (2008). Principles, Definitions and Model Rules of European Private Law. Draft Common Frame of Reference (DCFR). En https://www.law.kuleuven.be/personal/mstorme/DCFR.html.

Hesselink, M. (2010). The Concept of Good Faith. En A. Hartkampf, M. Hesselink, H. Ewoud, C. Mak y E. Du Perron (eds.), Towards a European Civil Code. Holanda: Wolters Kluwer (619-649 pp.).

Isler, E. (2020). La incidencia del Covid-19 en el ejercicio de la garantía legal. Revista De Derecho de la Universidad Católica del Norte (Coquimbo), 27, e4107. https://doi.org/10.22199/issn.0718-9753-2020-0005.

Laporta, F. (1999). Legal Principles. En G. Meggle (ed.), Actions, Norms and Values. Discussions with Georg Henrik von Wright. Berlín, Alemania: De Gruyter (279-284 pp.).

Larenz, K. (2002). Base del negocio jurídico y cumplimiento de los contratos. Granada, España: Editorial Comares.

Lehmann, M. (2020). Las medidas legislativas alemanas relacionadas con la crisis del Covid-19 en el ámbito del Derecho civil. Revista de Derecho Civil, 7(2), 3-7.

López, P. (2015). El Principio de Equilibrio Contractual en el Código Civil chileno y su particular importancia como fundamento de algunas instituciones del moderno Derecho de las obligaciones en la dogmática nacional. Revista chilena de 
derecho privado, 25, 115-181. https://doi.org/10.4067/S0718-

80722015000200004

López, P. (2018). La confianza razonable y su relevancia como criterio fundante de la tutela de ciertas anomalías o disconformidades acaecidas durante el iter contractual. Revista De Derecho Privado, 36, 127-168. https://doi.org/10.18601/01234366.n36.05

MacCormick, N. (2019). Razonamiento jurídico y Teoría del Derecho. Lima, Perú: Palestra.

Markesinis, B. S., Unberath, H. \& Johnston, A. (2006). The German Law of Contract: A Comparative Treatise. Oxford, Reino Unido: Bloomsbury Publishing.

Momberg, R. (2010). Teoría de la Imprevisión: La Necesidad de su Regulación Legal en Chile. Revista chilena de derecho privado, 15, 29-

64. https://dx.doi.org/10.4067/S0718-80722010000200002

Momberg, R. (2020). ¿Excesiva onerosidad o excesiva dificultad? Idealex.press. Santiago, Chile. En https://idealex.press/opinion/columnas/rodrigo-momberg-excesivaonerosidad-o-excesiva-dificultad/

Ortí, A. (2020). Riesgo contractual en los contratos privados tras el Covid-19: análisis, problemática y soluciones. España: Tirant Lo Blanch. En https://editorial.tirant.com/es/ebook/el-riesgo-contractual-en-los-contratosprivados-tras-el-covid-19-analisis-problematica-y-soluciones-antonio-ortivallejo-E000020005188.

Pantaleón, F. (2020). Arrendamiento de local de negocio y suspensión legal de actividades empresariales. Almacén de Derecho. Madrid, España. En https://almacendederecho.org/arrendamiento-de-local-de-negocio-y-suspensionlegal-de-actividades-empresariales/

Pazos, R. (2020). La respuesta del Derecho de obligaciones y contratos francés ante la pandemia de Covid-19. Revista de Derecho Civil, 7(2), 47-74.

Pinto, N. (2020). Covid-2019, Contratos de crédito, Contratos de arrendamiento y Contratos de viajes del Sector turístico en Portugal. Revista de Derecho Civil, $7(2), 89-102$.

Pizarro, C. (2005). La fuerza mayor como defensa del deudor. A propósito de la restricción de suministro de gas a Chile. Revista de Derecho Administrativo Económico, 14, 115-124.

Pizarro, C. (2010). Daños en la construcción, fuerza mayor y terremotos. Revista de derecho (Valparaíso), 34, 161-176. https://doi.org/10.4067/S071868512010000100004

Pizarro, C. (2017). Presentación. En A. Morales y A. Vidal (eds.), Los Principios Latinoamericanos de Derecho de los Contratos. Madrid, España: BOE.

Riofrío Martínez-Villalba, J. C. (2020). Estado de extremísima excepción reconocido tácitamente en la constitución y su aplicación al sector privado. Nuevo Derecho, 16(26): 1-14. 
Rivera, J. M. \& Barcia, R. (2016). Aspectos generales en torno a la cláusula rebus sic stantibus (teoría de la imprevisión), en España. Revista de derecho (Valparaíso), 47, 117-150. https://doi.org/10.4067/S0718-68512016000200004

San Martín, L. (2018). Las funciones de la razonabilidad en el Derecho Privado chileno. Revista de derecho (Valparaíso), 51, 173-198. https://doi.org/10.4067/S071868512018005000402

San Martín, L. (2019). Desastres naturales y responsabilidad civil. Identificación de los desafíos que presenta esta categoría de hechos dañinos. Revista de derecho (Valdivia), 32(2), 123-142. https://dx.doi.org/10.4067/S071809502019000200123

San Miguel, L (2018), El cambio de circunstancias y sus efectos en el contrato: especial atención a la propuesta de regulación de los principios latinoamericanos de derecho de los contratos. En Á. Vidal (dir.), G. Severin (ed.), Estudios de Derecho de Contratos en homenaje a Antonio Manuel Morales Moreno. Santiago de Chile: Thomson Reuters.

Schopf Olea, A. (2018). La buena fe contractual como norma jurídica. Revista chilena de derecho privado, 31, 109-153. https://dx.doi.org/10.4067/S071880722018000200109.

Stone, R. (2005). The Modern Law of Contract. Oxon, Reino Unido: Psychology Press.

Tapia, M. (2020). El Caso Fortuito o Fuerza Mayor, $3^{\text {a }}$ ed. Santiago de Chile: Thomson Reuters. En https://proview.thomsonreuters.com/launchapp/title/LALEY/2020/42494509/v1.

Vargas, I. (2020). Las medidas colombianas para mitigar los efectos del COVID-19 en materia civil. Revista de Derecho Civil, 7(2), 149-157.

Varsi, E.; Rosenvald, N. \& Torres, M. (2020). La pandemia de la covid-19, la fuerza mayor y la alteración de las circunstancias en materia contractual. Acta bioethica, 26(1), 29-36. https://dx.doi.org/10.4067/S1726-569X2020000100029

Viney, F. (2016). L'expansion du "raisonnable" dans la réforme du droit des obligations: Un usage déraisonnable? Recueil Dalloz, 33, 1940-1941.

Zúñiga, A. \& Chaparro, A. (2020). Especialistas plantean la necesidad de una ley para "casos fortuitos" ante efectos de la pandemia en contratos. El Mercurio Legal.

En: 1mercurio.com/Legal/Noticias/Noticias-yreportajes/2020/04/12/Especialistas-plantean-la-necesidad-de-una-ley-paracasos-fortuitos-ante-efectos-de-la-pandemia-en-contratos.aspx 